\title{
COMPARAÇÃO ENTRE ISOLADOS DE Helminthosporium oryzae Breda de Haan QUANTO A EXIGÊNCIAS NUTRICIONAIS E PADRÃO ISOENZIMÁTICO DE ESTERASES
}

\section{CECILIA GLADYS DIAAZ}

Bióloga

Orientador: Prof. Dr. IVAN PAULO BEDENDO

Dissertação apresentada à Escola Superior de Agricultura "Luiz de Queiroz", da Universidade de São Paulo, para obtenção do título de Mestre em Agronomia, Área de Concentração: Fitopatologia.

\author{
PIRACICABA \\ Estado de São Paulo - Brasil \\ Novembro - 1995
}


Dados Internacionais de Catalogação na Publicação (CIP)

DIVISĀO DE BIBLIOTECA E DOCUMENTAÇĀO - Campus “Luiz de Queiroz"/USP

Diaz, Cecilia Gladys

Comparação entre isolados de Helminthosporium oryzae Breda de Haan quanto à exigências nutricionais e padrāo isoenzimático de esterases / Cecilia Gladys Díaz. - - Piracicaba, 1995.

49 p. : il.

Dissertação (mestrado) - - Escola Superior de Agricultura Luiz de Queiroz, 1996.

Bibliografia.

1. Fungo fitopatogênico - Isolamento 2. Helmintosporiose do arroz 3. Isoen zima l. Título

CDD 632.44

633.18 


\section{COMPARAÇÃO ENTRE ISOLADOS DE \\ Helminthosporium oryzae Breda de Haan QUANTO \\ A EXIGÊNCIAS NUTRICIONAIS E PADRÃO ISOENZIMÁTICO DE ESTERASES}

CECILIA GLADYS DÍAZ

Aprovada em: 29.01.1996

Comissão julgadora:

Prof.Dr. Tasso Leo Krügner

ESALQ/USP

Prof.Dr. Sérgio Florentino Pascholati

ESALQ/USP

Prof.Dr. Breno Leite

UFPR/Curitiba

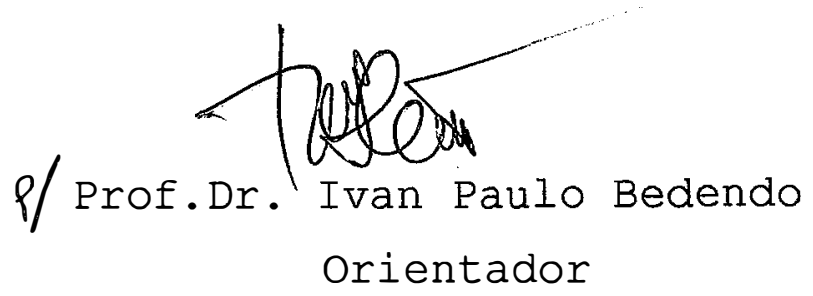


A meu marido Carlos Aníbal, pelo carinho e apoio constante 


\section{AGRADECIMENTOS}

Ao Prof. Dr. Ivan Paulo Bedendo, pela orientação e ensino.

A minha Mariana, pela sua paciência e compreensão.

A meus pais, Lilian e Julio, e irmãos, Fabiola e Norah, pelo total apoio e confiança.

A Kátia e Leonel, que facilitaram em muito minha adaptação no Brasil.

Aos amigos José Renato, Celia Regina, Marise, Nelson Sidnei, Hélio e Fabiana, pela sua amizade e convivência.

Um especial agradecimento ao Dr. Sérgio F. Pascholati pelas sugestões, incentivo e amizade.

A minha amiga Gisèle Fantin pela análise crítica do trabalho e sua amizade.

A Universidade Nacional de Tucumán pela oportunidade.

A minhas colegas da cátedra de Fitopatologia-Tucumán pela sua compreensão e apoio nos meus trabalhos que tiveram que assumir.

A Erna Bach, pesquisadora do Instituto Biológico de São Paulo, pela colaboração nos trabalhos de eletroforese.

A CAPES, pelo auxílio econômico através da concessão de uma bolsa de estudos.

Aos funcionários do Departamento de Fitopatologia, especialmente Rodolfo, Fernanda, Marina e Pedro da Silva, pela sua constante colaboração e amizade.

Aos professores do Departamento de Fitopatologia pelos seus ensinamentos e ótima convivência.

E a todos aqueles que participaram na culminação deste trabalho.

Sobre tudo, desejo meu eterno agradecimento a Deus, por estar me acompanhando nesta difícil opcão de minha vida, a qual. consegui levar sem angústias, pois Ele pois em meu caminho pessoas tão valiosas. 
SUMÁRIO

\section{Página}

LISTA DE FIGURAS $\ldots \ldots \ldots \ldots \ldots \ldots \ldots \ldots \ldots \ldots \ldots \ldots \ldots$

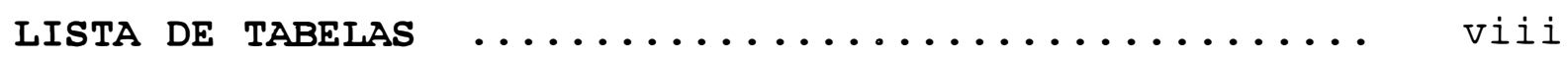

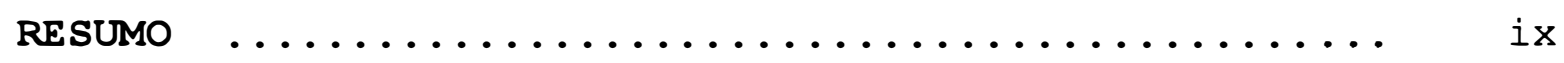

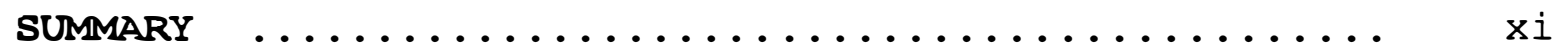

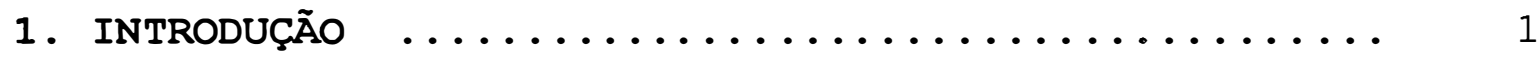

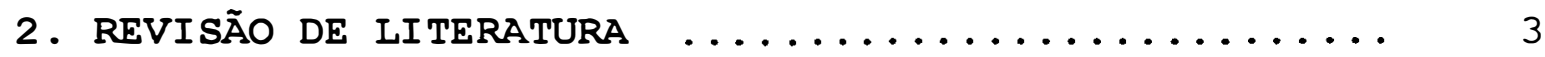

2.1. Requerimentos nutricionais ............ 4

2.2. Padrões eletroforéticos na diferenciação de isolados de fungos ..................... 7

3. MATERIAL E MÉtodos ...................... 10

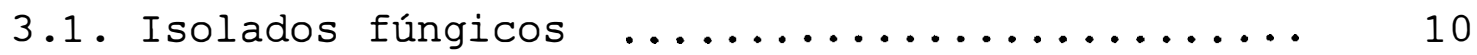

3.2. Estudos nutricionais $\ldots \ldots \ldots \ldots \ldots \ldots \ldots \ldots \ldots$

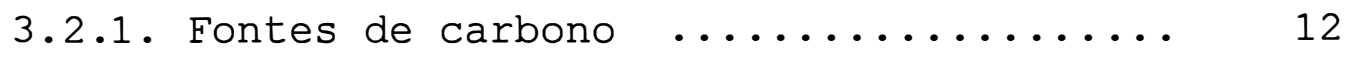

3.2.2. Fontes de nitrogênio .............. 13

3.2.3. Mistura de aminoácidos ............ 14

3.3. Caracterização eletroforética dos isolados de

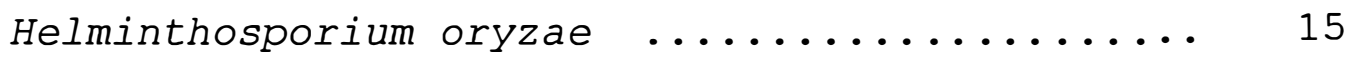

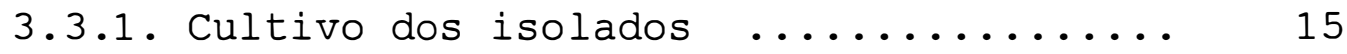

3.3.2. Extração de proteínas ............. 16

3.3.3. Quantificação de proteínas nas amostras 16

3.3.4. Preparo do gel de poliacrilamida ..... 17

3.3.5. Aplicação das amostras e corrida eletroforética ................. 18

3.3.6. Coloração do gel para atividade esteári-

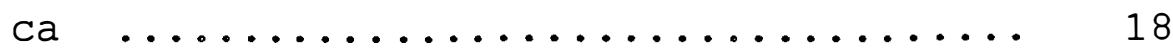

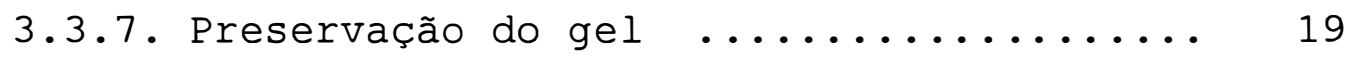

3.3.8. Análise do perfil eletroforético ..... 19 


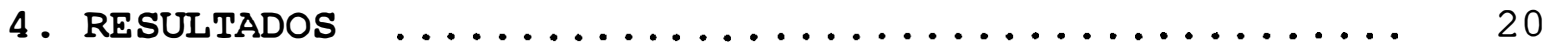

4.1. Estudo comparativo da influência da nutrição no crescimento de isolados de $H$. oryzae ........ 20

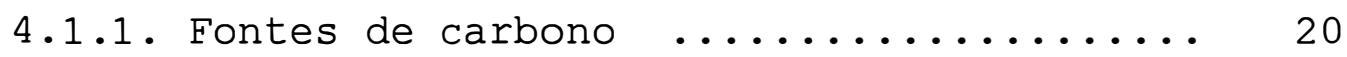

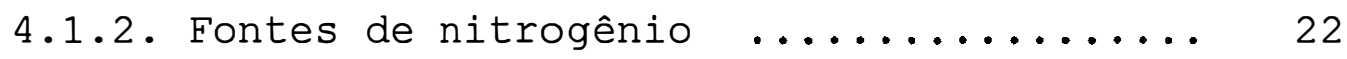

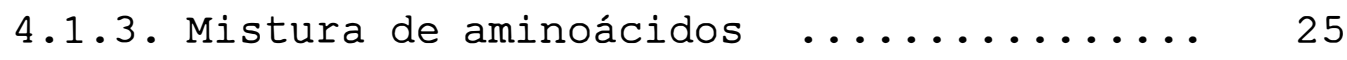

4.2. Efeito comparativo da nutrição na esporulação

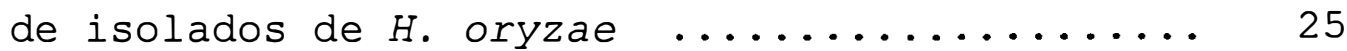

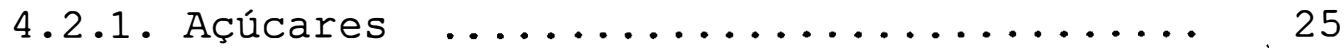

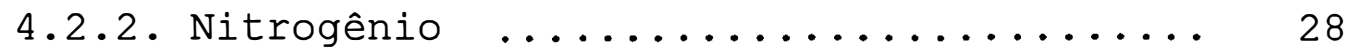

4.2.3. Mistura de aminoácidos .............. 28

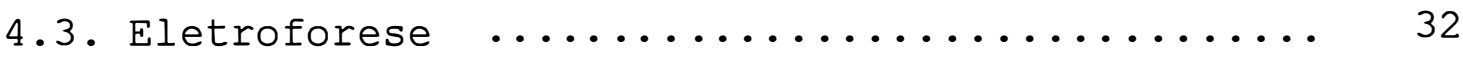

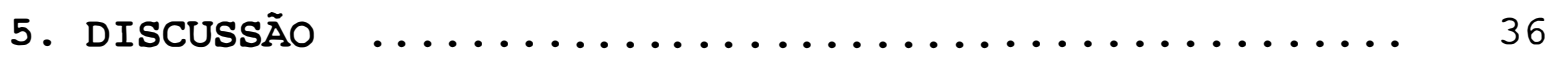

5.1. Efeito comparativo da nutrição no crescimento 36

5.2. Efeito comparativo da nutrição na esporulação 38

5.3. Eletroforese ........................ 40

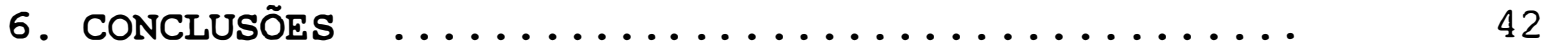

7. REFERÊNCIAS BIBLIOGRÁFICAS .............. 43 
IISTA DE FIGURAS

FIGURA N N $^{\circ}$

Página

01

Aspecto das colônias dos isolados esporulantes $(1=\mathrm{H}-1,2=\mathrm{HO}, 3=\mathrm{HO} 82-1$, $4=\mathrm{HOCB}, 5=\mathrm{H}-22,6=\mathrm{HOC})$ e não esporulantes $(7=\mathrm{HOP} 1,8=\mathrm{H}-23,9=\mathrm{HO}$ 899/3, 10= IAC HO) de H. oryzae crescidos em meio $\mathrm{BDA} \quad \ldots \ldots \ldots \ldots \ldots \ldots \ldots \ldots \ldots$

02 Esporulação $\left(10^{3}\right.$ esporos $\left./ \mathrm{cm}^{2}\right)$ dos isolados esporulantes de $H$. oryzae em meio mínimo suplementado com diferentes fontes de carbono, após 7 dias de incubação a $28{ }^{\circ} \mathrm{C}$. Médias seguidas pela mesma letra maiúscula ou minúscula não diferem entre si para o mesmo tratamento em cada isolado, ou mesmo isolado para diferentes tratamentos, respectivamente, pelo teste

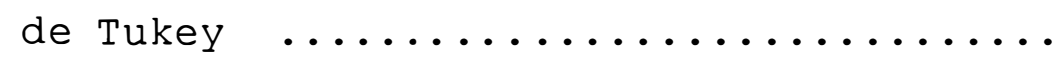

03 Esporulação $\left(10^{3}\right.$ esporos $\left./ \mathrm{cm}^{2}\right)$ dos isolados esporulantes de $H$. oryzae em meio mínimo suplementado com diferentes fontes de nitrogênio, após 7 dias de incubação a 28 ${ }^{\circ} \mathrm{C}$. Médias seguidas pela mesma letra maiúscula ou minúscula não diferem entre si para o mesmo tratamento em cada isolado, ou mesmo isolado para diferentes tratamentos, respectivamente, pelo teste

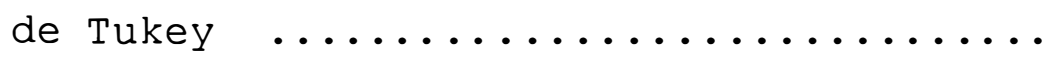


04 Esporulação $\left(10^{3}\right.$ esporos $\left./ \mathrm{cm}^{2}\right)$ dos isolados esporulantes de $H$. oryzae em meio mínimo suplementado com diferentes grupos de aminoácidos, após 7 dias de incubação a $28{ }^{\circ} \mathrm{C}$. Médias seguidas pela mesma letra maiúscula ou minúscula não diferem entre si para o mesmo tratamento em cada isolado, ou mesmo isolado para diferentes tratamentos, respectivamente, pelo teste de Tukey $\ldots \ldots \ldots \ldots \ldots \ldots \ldots \ldots \ldots \ldots$

05 A. Eletroforese em gel de poliacrilami$\mathrm{da}$ dos isolados esporulantes $(\mathrm{A}=$ HOCB, $B=H O 82-1, C=H O C, D=H O, E$ $=\mathrm{H} 22, \mathrm{~F}=\mathrm{H}-1)$ e não esporulantes A $1=\mathrm{IAC}-\mathrm{HO}, \mathrm{B} 2=\mathrm{HOP} 1, \mathrm{C} 3=\mathrm{HO}$ 899/3, D4 = H-23) de H. oryzae.

B. Diagrama eletroforético em gel de poliacrilamida dos isolados esporulantes e não esporulantes de $H$. oryzae

06 Densitometria dos isolados não esporulantes de $H$. oryzae. Leitura em

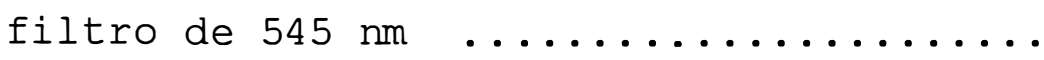

07 Densitometria dos isolados esporulantes de H. oryzae. Leitura em filtro de $545 \mathrm{~nm}$ 


\section{LISTA DE TABELAS}

TABELA $\mathrm{N}^{\circ}$

Página

01 Características e procedência dos isolados de Helminthosporium oryzae ......

02 Crescimento das colônias dos grupos de isolados esporulantes e não esporulantes de $H$. oryzae nas diferentes fontes de carbono

03 Crescimento das colônias dos grupos de isolados esporulantes e não esporulantes de $H$. oryzae nas diferentes fontes de nitrogênio $\ldots \ldots \ldots \ldots \ldots \ldots \ldots \ldots$

04 Crescimento das colônias dos isolados esporulantes e não esporulantes de $H$. oryzae nos grupos I e II de aminoácidos 
COMPARAÇÃO ENTRE ISOLADOS DE Helminthosporium oryzae Breda de Haan QUANTO A EXIGÊNCIAS NUTRICIONAIS E PADRÃO ISOENZIMÁTICO DE ESTERASES

\section{RESUMO}

Seis isolados esporulantes ( $\mathrm{H}-22$, $\mathrm{HO}, \mathrm{H}-1$, $\mathrm{HO}$ 82/1, HOCB, HOC) e quatro não esporulantes (HO 889/3, IAC HO, HOP1, H-23) de Helminthosporium oryzae (Cochliobolus miyabeanus), agente causal da mancha parda em arroz, foram comparados a nível nutricional (fontes de carbono: Lsorbose, D-frutose, L-arabinose, sacarose, D-maltose e amido; fontes de nitrogênio: neopeptona, caseína, Lasparagina, cloreto de amônio, sulfato de amônio e uréia; e uma mistura de aminoácidos) e a nível isoenzimático (esterases).

De maneira geral, observou-se que os isolados não esporulantes exibiram maior velocidade de crescimento que os esporulantes na maioria dos meios de cultivo.

Os carboidratos, com exceção da L(-) sorbose, permitiram excelente crescimento micelial, enquanto que todos os isolados de $H$. oryzae foram capazes de metabolizar as diferentes fontes de nitrogênio orgânico e inorgânico testadas, mas sulfato de amônio e cloreto de amônio mostraram-se como fontes inadequadas de nitrogênio, proporcionando menor crescimento.

As fontes de carbono e nitrogênio influenciaram de maneira variada a esporulação dos isolados, sendo que não foi possível apontar a melhor delas para a produção de conídios. No caso dos isolados não esporulantes, estes 
mantiveram tal condição frente às diferentes fontes nutricionais.

As comparações dos perfis isoenzimáticos de esterases permitiram visualizar diferenças entre os isolados, onde os não esporulantes exibiram uma maior variabilidade no número de bandas e posição no gel de poliacrilamida, enquanto que os esporulantes apresentaram um padrão mais homogêneo.

Assim, os isolados de Helminthosporium oryzae não foram diferenciados através das comparações auxanográficas estudadas, o que foi possível através do padrão isoenzimático de esterases. 


\title{
NUTRICIONAL REQUERIMENTS AND ISOENZIMATIC PATTERN AMONG ISOLATES OF Helminthosporium oryzae Breda de Haan.
}

\author{
Author: CECILIA G. DÍAZ
}

Adviser: PROF. IVAN PAULO BEDENDO

\section{SUMMARY}

Six sporulating isolates of Helminthosporium oryzae ( $\mathrm{H}-22$, $\mathrm{HO}, \mathrm{H}-1$, $\mathrm{HO} 82-1, \mathrm{HOCB}, \mathrm{HOC}$ ) and four non sporulating ones (HO 899/3, IAC-HO, HOP1, H-23) were compared at the nutricional level through the use of different carbon, nitrogen and aminoacid sources and at the isoenzimatic (sterase) level.

It was possible, in general, to differentiate the sporulating from the non-sporulating isolates, according to their growth rate, the non sporulating growing faster than the sporulating ones.

With the exception of $L(-)$ sorbose, all carbohidrates promoted excellent mycelial growth. All isolates were able to use the organic and inorganic sources of nitrogen tested. Ammonium sulphate and ammonium chloride were not good sources of nitrogen for mycelial growth.

The sporulation was variably influenced by carbon and nitrogen sources. None of them, however, could be chosen as the best source for sporulation. There was no stimulus of sporulation among the non-sporulating isolates by any source of carbon or nitrogen.

Differences among isolates were detected through their isoenzimatic profiles, specially between the nonsporulating and the sporulating groups. The sporulating isolates showed a more uniform pattern of bands than the 
non-sporulating ones. The last one exibited more variability in the number of bands and position in the polyacrilamide gel.

In conclusion, the results showed that the nutritional requeriments for carbon and nitrogen are not a good method for isolate differentiation, whereas the electrophoresis constitutes a usefull tool for this porpose. 


\section{INTRODUÇÃO}

A capacidade de utilização de diferentes fontes de carbono e nitrogênio pelos fungos é usada não só como um critério taxonômico, bem como uma maneira de se caracterizar fisiologicamente gêneros, espécies, raças e isolados de fungos fitopatogênicos (GEORG \& CAMP, 1957; DUDIENAS, 1991).

Helminthosporium oryzae Breda de Haan, agente causal da mancha parda em arroz, é um fungo imperfeito, com conídios do tipo fragmosporo, dispostos em conidióforos livres, sendo a fase sexual Cochliobolus miyabeanus (Ito \& Kuribayashi) Drechsler e Datur não relatada ainda no Brasil. Em meios de cultivo, o fungo usualmente forma micélio cotonoso, variando as tonalidades entre o cinza claro ao preto, sendo essa variabilidade reflexo não só da condição heterocariótica do fungo, mas também dos fatores físicos e nutricionais. A variabilidade se expressa no aspecto da colônia, bem como na taxa de crescimento e esporulação, observando-se com freqüência isolados de $H$. oryzae que esporulam pouco ou perdem completamente esta capacidade quando cultivados em meios de cultura (CHATTOPADHYAY \& DAS GUPTA, 1965). 
Outra maneira de se evidenciar a variabilidade entre os isolados de uma espécie de fungo é através da comparação dos padrões protéicos, com o uso da eletroforese, técnica que tornou-se grande auxiliar na Fitopatologia. Segundo ALFENAS (1991), a análise eletroforética de proteínas e isoenzimas tem se mostrado como técnica bastante promissora para a identificação de raças e detecção de variabilidade de fungos fitopatogênicos. Além disso, pode ser útil também na distinção de espécies com pequenas diferenças morfológicas ou que não esporulam em meio de cultivo.

Em vista da escassez de estudos de natureza nutricional e isoenzimática com isolados de $H$. oryzae, e da importância da indução da esporulação para testes de patogenicidade, esses aspectos podem contribuir para um maior conhecimento deste importante fungo fitopatogênico. Portanto, o presente trabalho procurou:

a) Comparar, através do crescimento vegetativo, os diferentes isolados de $H$. oryzae quanto a capacidade de usar diferentes fontes de carbono e nitrogênio;

b) Determinar os efeitos dessas fontes nutricionais na esporulação do fungo:

c) Comparar os isolados fúngicos com base no perfil isoenzimático de esterases. 


\section{REVISÃO DE LITERATURA}

A mancha parda do arroz é uma doença de distribuição mundial, tendo sido reportada em todos os países produtores dessa cultura (OU, 1985).

SANTOS \& SANTOS (1995) fizeram um levantamento das principais doenças que ocorrem nas cultivares Metica 1 e Javaé durante a safra 94/95 no Estado de Tocantins, terceiro maior produtor de arroz do Brasil. Observaram que a mancha parda apresentou a maior porcentagem de incidência (35\%), seguido da mancha em grãos (34\%), brusone das folhas (27\%), brusone do pescoço (18\%) e escaldadura das folhas $(7,6 \%)$. Segundo PRABHU (1995), a brusone (Pyricularia oryzae) e a mancha em grãos (Drechslera oryzae, Phoma sorghina) são as principais doenças que causam baixa produtividade e qualidade de grãos no Brasil.

O agente causal da mancha parda, Helminthosporium oryzae Breda de Haan, é um fungo imperfeito da Ordem Moniliales, sendo a fase perfeita, o ascomiceto Cochliobolus miyabeanus (Ito \& Kuribayashi) Drechsler e Datur, ainda não relatada no Brasil.

Entre os isolados de Helminthosporium oryzae existe uma grande variação quanto as características culturais, nutricionais e de patogenicidade. Muitos pesquisadores relatam que Helminthosporium oryzae apresenta baixa capacidade de esporulação em função das condições ambientais e nutricionais em que é incubado e, segundo CHATTOPADHYAY \& DAS GUPTA (1965), a maioria dos isolados de Helminthosporium oryzae não esporula ou esporula muito pouco em meio de cultura. 
SINGH (1967) comparando isolados esporulantes e não esporulantes de Helminthosporium oryzae, observou que os isolados não esporulantes produziam grande quantidade de clamidósporos em ágar-cenoura, ágar-soja e ágar-feijão, e que várias fontes de carbono, nitrogênio, hormônios, vitaminas e agentes mutagênicos falharam na indução da esporulação.

Pela dificuldade na obtenção de isolados esporulantes de $H$. oryzae para inoculações artificiais, SHERF et al. (1947) indicaram que fragmentos de micélio poderiam ser usados como inóculo, sendo que eles não possuem a mesma capacidade invectiva dos conídios.

\subsection{Requerimentos nutricionais}

Os estudos auxanográficos são aqueles destinados a conhecer os requerimentos nutricionais dos microrganismos. Estes tiveram seu grande aporte na genética de fungos, através da obtenção e do uso de mutantes auxotróficos. BEADLE \& TATUM (1941) isolaram os primeiros mutantes auxotróficos a partir de Neurospora sp., derivando desses estudos originais, a clássica teoria de"um gene uma enzima". AZEVEDO (1972) explica que a caracterização dos auxotróficos em geral é feita pela técnica de auxanografia, que consiste em semear conídios do auxotrófico a ser caracterizado em meio mínimo e adicionar a fonte de nutrientes de interesse (aminoácidos, purinas e pirimidinas, vitaminas, etc.). Um halo de crescimento ao redor de uma dessas substâncias indicará se o mutante requer ou não, por exemplo aminoácido, uma base nitrogenada ou uma vitamina. 
Os requerimentos nutricionais, de acordo com GEORG \& CAMP (1957), mostram-se como uma ferramenta complementar nos estudos taxonômicos. Segundo esses autores, a caracterização pela diferença nos requerimentos nutricionais específicos é de grande valia na identificação de fungos, especialmente naquelas espécies de difícil esporulação ou com características morfológicas semelhantes.

Em função destes estudos nutricionais, KIMATI (1975) demonstrou que Colletotrichum falcatum pode ser distinguido de C. graminicola por ser deficiente em biotina. Do mesmo modo, DUDIENAS (1990) observou que Colletotrichum gossypii var. cephalosporioides pode ser diferenciado de C. gossypii por ser deficiente em asparagina ou ácido aspártico.

Valendo-se destes estudos nutricionais, com a finalidade de comparar isolados de fungos ou niveis taxonômicos, pode-se observar variabilidade na capacidade de utilização de diferentes fontes de carbono e nitrogênio. Chem et al. ${ }^{1}$, citado por OU (1985) observou variações no crescimento micelial entre raças de Helminthosporium oryzae em resposta a diferentes açúcares testados. SREEDHARAM \& MENON (1974) observaram também variações na taxa de crescimento e esporulação de isolados de $H$. oryzae em meio mínimo contendo glicose como fonte de carbono e peptona como fonte de nitrogênio.

\footnotetext{
${ }^{1}$ CHEN,Y.S.; REN,H.C.; FANG,C.T. Studies on the carbon and nitrogen nutrition of Pyricularia oryzae and Helminthosporium oryzae. Acta Phytopathologica Sinica, 7: 165-174, 1964.
} 
Outros autores como MALCA \& ULLUSTRUP (1962) constataram variações na taxa de crescimento e esporulação entre isolados de Helminthosporium turcicum e H. carbonum frente as diferentes fontes de carbono e nitrogênio estudadas.

KLECAN et al. (1990), através das propriedades nutricionais acompanhando a outros estudos, concluíram que o isolado Michigan de Tilletiopsis devia ser considerado como T. pallencens.

Otsuka et al. ${ }^{2}$, citado por OU (1985) através desses estudos nutricionais pôde classificar os isolados de Pyricularia oryzae em 13 tipos bioquímicos.

TABER et al. (1968), também realizaram um estudo nutricional comparativo em Alternaria raphani, A. brassicae e A. brassicicola, observando que $A$. brassicae cresceu mais rapidamente em amido, ao passo que $A$. brassicicola cresceu mais rapidamente em galactose. HASIJA (1970) observou diferenças entre duas espécies de Alternaria visto que $A$. tenui exibiu a capacidade de assimilar o ácido aspártico, enquanto que $A$. citri, não assimilava esse aminoácido.

BONNELL \& LEVETIN (1981), encontraram que raças de Epicoccum nigrum diferiram na esporulação e no crescimento micelial quando crescidas em diferentes fontes de carbono e nitrogênio. Enquanto que, CAO \& CRAWFORD (1993) ao comparar

${ }^{2}$ OTSUKA,H.; TAMARI,K.; OGASAWARA,N. Variability of Pyricularia oryzae in culture. In: The rice blast disease,69-109. Baltimore, Johns Hopkins Press. 1965. 
4 isolados de Pisolithus tinctorius, pela capacidade de utilizar fontes de carbono, observaram que a glicose, mannose e celobiose proporcionaram um rápido crescimento micelial nos 4 isolados. Por sua vez, a frutose foi usada somente por 2 isolados.

\subsection{PADRÕES ELETROFORÉTICOS NA DIFERENCIAÇÃO DE ISOLADOS DE FUNGOS}

O uso da eletroforese na separação de proteínas de fungos tem recebido muita atenção nos últimos anos, como explica BONDE et al. (1993). A análise de isoenzimas através da eletroforese mostra-se como uma poderosa técnica bioquímica que tem numerosas aplicações em fitopatologia, sendo um método simples, eficiente e econômico na resolução de muitos problemas taxonômicos e fitopatológicos. Um bom exemplo diz respeito as espécies de Colletotrichum: C.gloesoporioides, C. fragariae e C. acutatum, as quais são difíceis de serem identificadas através da morfologia, porém podendo serem distinguidas com o uso da eletroforese de enzimas específicas. ALFENAS (1991) considera esta técnica útil na distinção de espécies de fungos com pequenas diferenças morfológicas ou que não esporulam em meio de cultura.

A eletroforese vem sendo aplicada à todos os membros dos principais grupos de fungos. CRUICKSHANK \& PITT (1987) reordenaram as espécies de Penicillium através da análise das enzimas poligalacturonase, esterase da pectina, amilase e ribonuclease extraídas do micélio. 
MAGAE et al. (1990) ao compararem diferentes métodos eletroforéticos a fim de caracterizarem espécies de Pleurotus sp, concluíram que a eletroforese em gél de poliacrilamida mostrava-se como a mais conveniente.

A atividade de esterase em gél de poliacrilamida, mostrou-se adequada na caracterização dos isolados de Alternaria solani, Exerohilum turcicum e Colletotrichum gloeosporioides (FANCELLI,1991; BACH, 1991; GÓES, 1995, respectivamente).

VALIM-LABRES et al. (1995) através do sistema esterase, observaram uma grande variabilidade isoenzimática em populações de Bipolaris sorokiniana.

A fim de comparar os padrões eletroforéticos das proteínas extraídas de esporos e micélio de duas espécies de Drechslera (D. erythrospilum e $D$. teres) em gél de poliacrilamida, SHIPTON \& MCDONALD (1970) observaram diferenças no número, intensidade da cor e largura das bandas entre ambos padrões dependendo da espécie.

LLOYD et al. (1971) consideram que -a maior atividade de esterases está associada aos processos de esporulação, sendo maior no momento da produção dos conídios e não durante o desenvolvimento dos conidióforos. Essa observação foi confirmada durante a avaliação da atividade esterásica em Candida lipolytica e Aspergillus niger. CUNNIGHANNN \& KUICAK (1986) valendo-se dessa observação usaram a atividade da esterase como um marcador de esporulação em Colletotrichum sp, encontrando uma estreita relação entre a maior atividade da esterase durante a fase conidial do que no micélio vegetativo.

Finalmente, com base no levantamento bibliográfico efetuado podê-se constatar que não foi possível encontrar 
nenhuma citação referente a Helminthosporium oryzae, porém, as referências de outros gêneros de fungos forneceram uma base para a metodologia empregada e interpretação dos resultados obtidos no presente trabalho. 


\section{MATERIAL E MÉTODOS}

O presente trabalho foi desenvolvido no Departamento de Fitopatologia da Escola Superior de Agricultura "Luiz de Queiroz" da Universidade de São Paulo, em Piracicaba, Estado de São Paulo.

\subsection{Isolados fúngicos}

Foram utilizados 10 isolados de Helminthosporium oryzae procedentes dos Estados de São Paulo, Goiás e Rio Grande do Sul, os quais são discriminados na Tabela 01, cujo crescimento em batata dextrose ágar (BDA) está ilustrado na Figura 01 .

Tabela 01- Características e procedência dos isolados de Helminthosporium oryzae.

\begin{tabular}{llll}
\hline \multicolumn{1}{c}{ ISOLADOS } & CARACTERÍSTICAS & PROCEDÊNCIA & \\
\hline H-22 & esporulante & Rio Grande do Sul \\
HO & esporulante & Goiás & \\
H-1 & esporulante & Rio Grande do Sul \\
HO $82 / 1$ & esporulante & Goiás & \\
HOCB & esporulante & São Paulo & \\
HOC & esporulante & São Paulo \\
HO 889/3 & não esporulante & Goiás \\
IAC HO & não esporulante & São Paulo & \\
HOP1 & não esporulante & São Paulo & \\
H-23 & não esporulante & Rio Grande do Sul \\
\hline \hline
\end{tabular}




\section{Esporulantes}

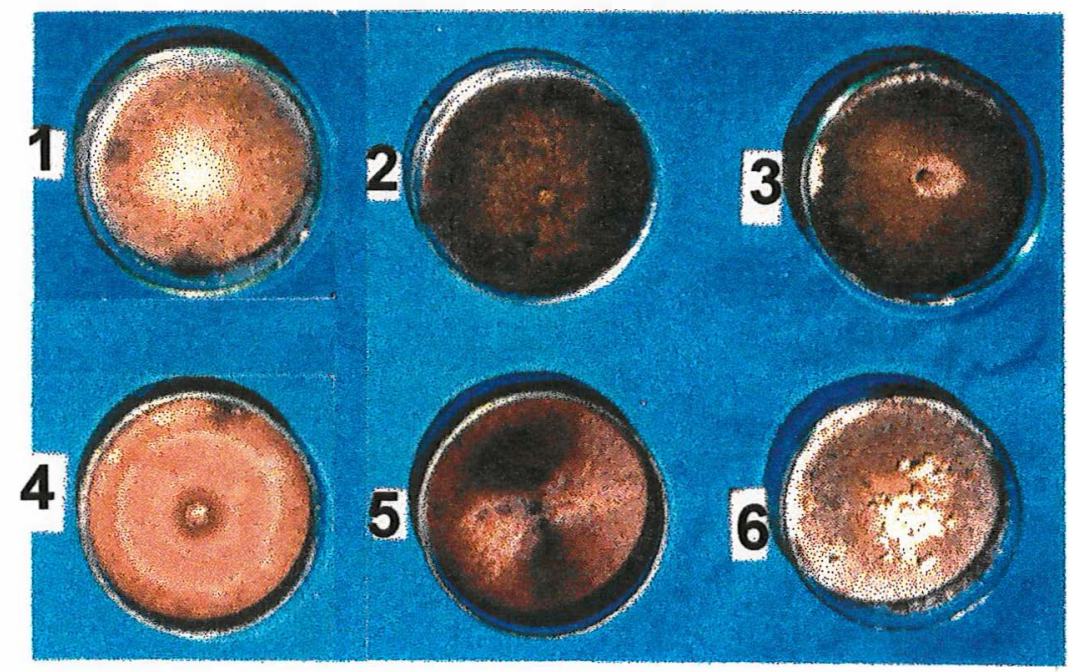

Não esporulantes

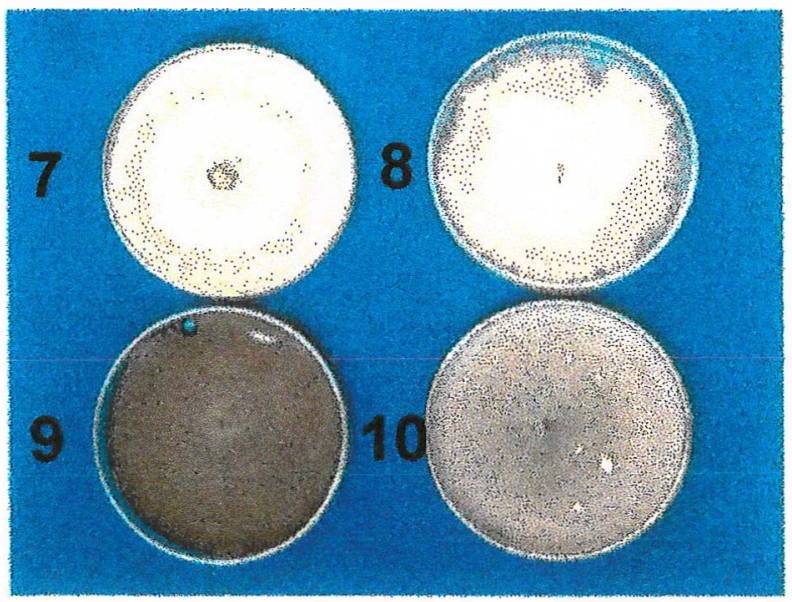

Figura 01. Aspecto das colônias dos isolados esporulantes $(1=\mathrm{H}-1,2=\mathrm{HO}, 3=\mathrm{HO}$ $82-1,4=\mathrm{HOCB}, 5=\mathrm{H}-22,6=\mathrm{HOC})$ e não esporulantes $(7=\mathrm{HOP} 1,8=\mathrm{H}-23,9=\mathrm{HO}$ $899 / 3,10=$ IAC HO) de $H$. oryzae crescidos em meio BDA. 


\subsection{Estudos nutricionais}

Os estudos foram conduzidos em meio mínimo (MM) basal sólido, preparado de acordo com PONTECORVO et al. (1953), modificado por KIMATI (1975), cuja composição foi a seguinte: glicose $10 \mathrm{~g} ; \mathrm{NaNO}_{3} 6 \mathrm{~g} ; \mathrm{KH}_{2} \mathrm{PO}_{4} 1,5 \mathrm{~g} ; \mathrm{KCl} 0,5 \mathrm{~g}$; $\mathrm{MgSO}_{4} \cdot 7 \mathrm{H}_{2} \mathrm{O} 0,5 \mathrm{~g}$; solução de micronutrientes $1 \mathrm{ml}$; ágar Difco $15 \mathrm{~g}$; água destilada $1000 \mathrm{ml}$. A solução de micronutrientes (LILLY \& BARNETT, 1951) continha: $\mathrm{Fe}\left(\mathrm{NO}_{3}\right)_{3} \cdot 9 \mathrm{H}_{2} \mathrm{O} 723,4 \mathrm{mg} ; \mathrm{ZnSO}_{4} \cdot 7 \mathrm{H}_{2} \mathrm{O} 439,8 \mathrm{mg} ; \mathrm{MnSO}_{4} \cdot 4 \mathrm{H}_{2} \mathrm{O} 203,0$ mg em $1000 \mathrm{ml}$ água destilada, sendo a solução clarificada com ácido sulfúrico.

A partir de cada isolado de $H$. oryzae, crescendo durante 10 dias em meio de batata-dextrose-ágar (BDA 2\%), foram retirados discos de micélio $(0,6 \mathrm{~cm}$ de diâmetro) obtidos das margens das colônias. Cada disco foi transferido para o meio mínimo, sendo feitas 2 repicagens sucessivas nesse meio antes de se proceder aos estudos comparativos.

\subsubsection{Fontes de carbono}

Com o objetivo de se comparar os isolados de $H$. oryzae através da capacidade de utilização de diversas fontes de açúcares, e se determinar a existência de algum efeito da mesma em estimular a esporulação foram conduzidos os seguintes ensaios:

Em substituição à glicose do meio mínimo, foram utilizados os seguintes açúcares: a) Monossacarídeos: Lsorbose; D-frutose e L-arabinose; b) Dissacarideos: sacarose e D-maltose; c) Polissacarídeo: amido. Cada açúcar foi adicionado individualmente na quantidade de $10 \mathrm{~g}$ por 
litro ao meio mínimo. O meio mínimo com glicose foi utilizado como controle.

$\mathrm{O}$ pH de todos os meios foi ajustado para 5,8 antes da autoclavagem, sendo usadas placas de Petri de vidro $(9 \mathrm{~cm}$ de diâmetro). No experimento, um disco de micélio, obtido a partir de colônias com 7 dias de idade, foi colocado no centro das placas contendo o meio correspondente a cada tratamento. Após a repicagem, as placas foram mantidas durante 7 dias sob fotoperíodo de 14 horas a $28 \pm 2{ }^{\circ} \mathrm{C}$.

A avaliação do crescimento foi feita através da medição diária do diâmetro das colônias.

Para se determinar a capacidade de esporulação, os conídios foram coletados no sétimo dia, através da adição de $20 \mathrm{ml}$ de água destilada contendo uma gota de Tween 20 em cada placa. A contagem foi feita com o auxílio de uma câmara de Neubauer e a esporulação expressa em esporos $/ \mathrm{cm}^{2}$. Estes resultados foram transformados em $\sqrt{x+0,5}$ para fins de análise estatística.

O delineamento experimental foi inteiramente casualizado com 4 repetições. Foi realizada análise estatística para o crescimento entre os grupos de isolados esporulantes e não esporulantes, em cada carboidrato.

\subsubsection{Fontes de nitrogênio}

A fim de se comparar os diferentes isolados de $H$. oryzae através da capacidade de utilização de fontes orgânicas e inorgânicas de nitrogênio e se verificar o efeito da mesma na produção de esporos, foram conduzidos os seguintes estudos: 
Em substituição ao $\mathrm{NaNO}_{3}$ do meio mínimo, foram estudadas diferentes fontes de nitrogênio: a) nitrogênio orgânico: neopeptona; caseína; L-asparagina; b) sais inorgânicos: cloreto de amônio; sulfato de amônio e uréia. Cada fonte foi adicionada individualmente ao $\mathbf{M}$, de maneira a se fornecer $0,2 \mathrm{~g} / \mathrm{l}$.

$\mathrm{O} \mathrm{pH}$ de todos os tratamentos foi ajustado a 5,8 antes da autoclavagem, sendo a repicagem, condições de incubação, avaliação do crescimento micelial e esporulação conduzidos como descritos nos estudos envolvendo fontes de carbono. Também foi realizada análise estatística entre os grupos esporulantes e não esporulantes.

\subsubsection{Misturas de aminoácidos}

As misturas de aminoácidos foram divididas em aminoácidos do grupo I e grupo II, segundo os resultados obtidos por PELLETIER \& KEITT (1954). O grupo I foi representado por DL-alanina, L-arginina, L-ácido glutâmico, L-glicina, L-prolina e L-tirosina, enquanto que o grupo II compreendia L-asparagina, DL-ácido aspártico, DLisoleucina, DL-leucina, DL-fenilalanina e DL-serina.

A quantia de cada aminoácido adicionada ao meio $\mathbf{M}$ foi calculada visando o fornecimento de 0,2 g $\mathrm{N} / \mathrm{l}$.

$0 \mathrm{pH}$ de todos os meios foi ajustado a 5,8 antes da autoclavagem, sendo a repicagem, condições de incubação, avaliação do crescimento micelial, esporulação e delineamento experimental, conduzidos da mesma maneira que nos estudos envolvendo fontes de açúcares. Foi feita análise estatística entre os grupos de isolados esporulantes e não esporulantes para o crescimento 
micelial, como nos estudos envolvendo fontes de carboidratos e fontes de nitrogênio.

\subsection{Caracterização eletroforética dos isolados de Helminthosporium oryzae.}

\subsubsection{Cultivo dos isolados}

A fim de se extrair as proteínas e se analisar o perfil eletroforético, os isolados de $H$. oryzae foram cultivados em $30 \mathrm{ml}$ de meio líquido batata-dextrose (BD). De cada isolado foram repicados três discos com micélio obtidos da periferia de colônias com 7 dias de idade, crescendo em meio mínimo a $28{ }^{\circ} \mathrm{C}$. A seguir, procedeu-se a incubação dos fungos a $28{ }^{\circ} \mathrm{C}$ durante 10 dias, no escuro. Após esse período, o micélio contido em cada erlenmeyer $(125 \mathrm{ml})$ foi colhido separadamente, através de filtração em funil Buchner e papel de filtro Whatman $n^{\circ} 1$, previamente pesado. O micélio de cada isolado foi lavado com água destilada estéril, para a remoção dos resíduos de meio de cultivo, posteriormente secos à temperatura ambiente durante 2 horas e posterirmente pesados, obtendo-se assim o peso fresco (PF).

Para a obtenção do peso seco (PS), amostras de micélio fresco foram colocadas em frascos de vidro para penicilina, previamente secos a $80^{\circ} \mathrm{C} / 24 \mathrm{~h}$ e tarados. As amostras foram mantidas em estufa a $80^{\circ} \mathrm{C}$, procedendo-se a sua pesagem a cada intervalo de 1 hora até a obtenção de peso constante (GARRAWAY \& EVANS, 1984). Mediante avaliações sucessivas verificou-se que $1 \mathrm{~g}$ de micélio fresco correspondia a $74 \mathrm{mg}$ em peso seco. 


\subsubsection{Extração de proteínas}

Para extração de proteínas, amostras equivalentes a $74 \mathrm{mg}$ de peso seco de micélio dos isolados de H. oryzae foram trituradas manualmente em almofariz, em banho de gelo, com $1 \mathrm{ml}$ de tampão Tris-glicina 0,125 M (pH 8,2) contendo $10 \mathrm{~g}$ de sacarose e $300 \mathrm{mg}$ de polivinilpirrolidona (PVP), conforme utilizado por BACH (1991). Após a trituração, as amostras foram mantidas a $4{ }^{\circ} \mathrm{C}$ durante $4 \mathrm{~h}$ e posteriormente centrifugadas a $16.000 \mathrm{~g}$ durante 10 minutos. o sobrenadante obtido representou o extrato protéico.

\subsubsection{Quantificação de proteínas nas amostras}

A concentração de proteínas nos extratos foi determinada quantitativamente através do método de Lowry (LOWRY et al., 1951). O método consiste em adicionar a cada $0,2 \mathrm{ml}$ das amostras, $1 \mathrm{ml}$ de solução reagente $\mathrm{C}$, que compreende uma mistura da solução reagente $B$ e de uma solução $2 \%$ de carbonato de sódio em hidróxido de sódio 0,1 N, na proporção de 1:50, respectivamente. A solução B foi preparada misturando-se alíquotas iguais de uma solução 1\% de sulfato de cobre pentahidratado em água destilada, e de uma solução 2 o de tartarato de sódio em água destilada. Em seguida, as amostras contendo a solução reagente $\mathrm{C}$, foram agitadas a temperatura ambiente $e$, após 10 minutos adicionou-se 0,1 $\mathrm{ml}$ de reagente Folin Ciocateau 2N (Quell Ind. Quím. São Paulo, SP), previamente diluído em água destilada $(1: 1, \mathrm{v} / \mathrm{v})$. As amostras foram agitadas vigorosamente, e após 30 minutos procedeu-se a determinação 
das respectivas absorbâncias em espectrofotômetro (UV - VIS Varion Techtron 635), no comprimento de onda de $500 \mathrm{~nm}$.

A concentração de proteínas em cada amostra foi expressa em ug de soro-albumina bovina (SAB) por ml (Sigma Chem. Co.) e foi determinada utilizando-se uma curva padrão com diferentes concentrações de SAB, variando de 20 a 500 $\mathrm{ug} / \mathrm{ml}$.

\subsubsection{Preparo do gel de poliacrilamida}

O processo consta de uma reação de polimerização entre o monômero acrilamida ( $A A$ ) e metileno-bis-acrilamida (BIS) na concentração de 5\%. Após a dissolução da AA e do BIS em tampão Tris-glicina 0,125 M (pH 8,2) acrescentou-se $0,1 \mathrm{ml}$ de tetrametiliamina (TEMED) e 2,8 $\mathrm{ml}$ de persulfato de amônia a 2 \%. A mistura foi colocada imediatamente entre placas, deixando-se a temperatura ambiente durante um período de 4 a 6 horas para polimerização completa. As duas placas (19 x 19,5 cm), sendo uma de vidro e outra de polietileno, foram separadas entre si por um espaçador de polietileno de $2 \mathrm{~mm}$ de espessura e a seguir presas por presilhas. O espaçador continha incluso, na parte superior, um pente para 12 amostras. Finda a polimerização completa do gel, o espaçador foi retirado e a placa de polietileno removida cuidadosamente, permanecendo o gel na placa de vidro. Esta placa foi transferida à uma cuba de sistema horizontal contendo tampão Tris-glicina 0,125 M (pH 8,2), fazendo-se uma ponte iônica do gel com a solução através de papel Whatman $n^{\circ} 3$. 


\subsubsection{Aplicação das amostras e corrida eletroforética}

Em cada cavidade do gel formada pelo pente, foram aplicados 20 ul do extrato contendo 350 ug de proteínas em equivalente de SAB. A corrida foi realizada em aparelho horizontal (Permatron), mantendo-se a corrente constante de $5 \mathrm{~mA}$ até $\mathrm{c}$ corante marcador atingir $\circ$ gel de corrida, passando depois para $10 \mathrm{~mA}$ até o final da corrida. O corante marcador utilizado foi o azul de bromofenol a 0,25\% em tampão Tris-glicina $0,125 \mathrm{M}(\mathrm{pH} 8,2)$ contendo sacarose a 10\%. A corrida eletroforética foi realizada à temperatura de $4^{\circ} \mathrm{C}$. As amostras dos isolados foram corridas em duplicatas e repetidas três vezes.

\subsubsection{Coloração do gel para atividade esterásica}

Após a corrida eletroforética, o gel foi retirado da placa e imerso imediatamente em solução corante para esterase. O método de coloração de esterase consistiu em dissolver $50 \mathrm{mg}$ de "Fast red TR" em $100 \mathrm{ml}$ de tampão fosfato 0,1 M (pH 6,5) acrescido de $2 \mathrm{ml}$ de solução $1 \%$ de naftilacetato em 50\% de acetona. A incubação foi realizada por uma hora até o aparecimento das bandas, sendo depois fixado com ácido acético 7\% (BACH, 1991). 


\subsubsection{Preservação do gel}

Após a coloração, o gel foi imerso em solução de metanol, ácido acético e água na proporção de 50:75:100 (v/v/v), contendo $10 \%$ de glicerina (v/v) durante $1 \mathrm{~h}$. Duas folhas de papel celofane foram colocadas nesta solução por alguns minutos. A seguir, recobriu-se uma placa de vidro $(18 \times 15 \mathrm{~cm})$ com uma das folhas de papel celofane tendo-se - cuidado de dobrar as duas bordas laterais para baixo e evitar que ficassem bolhas de ar sob o papel. O gel foi colocado sobre esta placa e, adotando-se os mesmos procedimentos com a segunda folha de papel recobriu-se o gel, deixando-o secar à temperatura ambiente. Depois da secagem, retirou-se o gel da placa de vidro, recortando-se o excesso de papel celofane e armazenando-se o mesmo.

\subsubsection{Análise do perfil eletroforético}

Os perfis foram analisados com base no número, posição $(\mathrm{Rm}=$ mobilidade relativa) $\mathrm{e}$ intensidade das bandas, sendo a interpretação dos resultados realizadas mediante a observação direta dos géis e através de diagrama eletroforético resultante da densitometria (densitômetro com filtro de $545 \mathrm{~nm})$. 


\section{RESULTADOS}

4.1. Estudo comparativo da influência da nutrição no crescimento de isolados de H. oryzae

\subsubsection{Fontes de carbono}

$\mathrm{Na}$ Tabela 02 são apresentados os resultados do crescimento diametral dos isolados não esporulantes e esporulantes de $H$. oryzae, crescendo em meio mínimo suplementado com diferentes açúcares como fonte de carbono. Verificou-se que todos os isolados exibiram boa capacidade de utilização da maioria dos açúcares, exceto a L(-) sorbose, que foi pobremente assimilada.

Entre os isolados não esporulantes, O HOP1, H-23 e IAC-HO apresentaram crescimento pouco menor no meio ao qual foi adicionado maltose, sendo que entre eles o isolado $\mathrm{H}-23$ foi o de menor crecimento.

Entre os isolados esporulantes, a maioria dos açúcares, exceto a sorbose, proporcionou um crescimento homogêneo e com maior diâmetro da colônia para o isolado H22, inclusive o meio mínimo. O isolado $\mathrm{H}-1$ apresentou em geral um menor diâmetro das colônias em relação aos demais isolados, seguido do HOC. O amido foi um açúcar que favoreceu o crescimento de quase todos os isolados. O isolado HO apresentou melhor crescimento em meio mínimo suplementado com amido, o qual não diferiu do crescimento em sacarose e frutose. HOB cresceu melhor em sacarose, amido e frutose, sendo que este crescimento não diferiu daquele em maltose; arabinose foi uma das piores fontes de carbono, proporcionando o menor crescimento. Para o isolado 


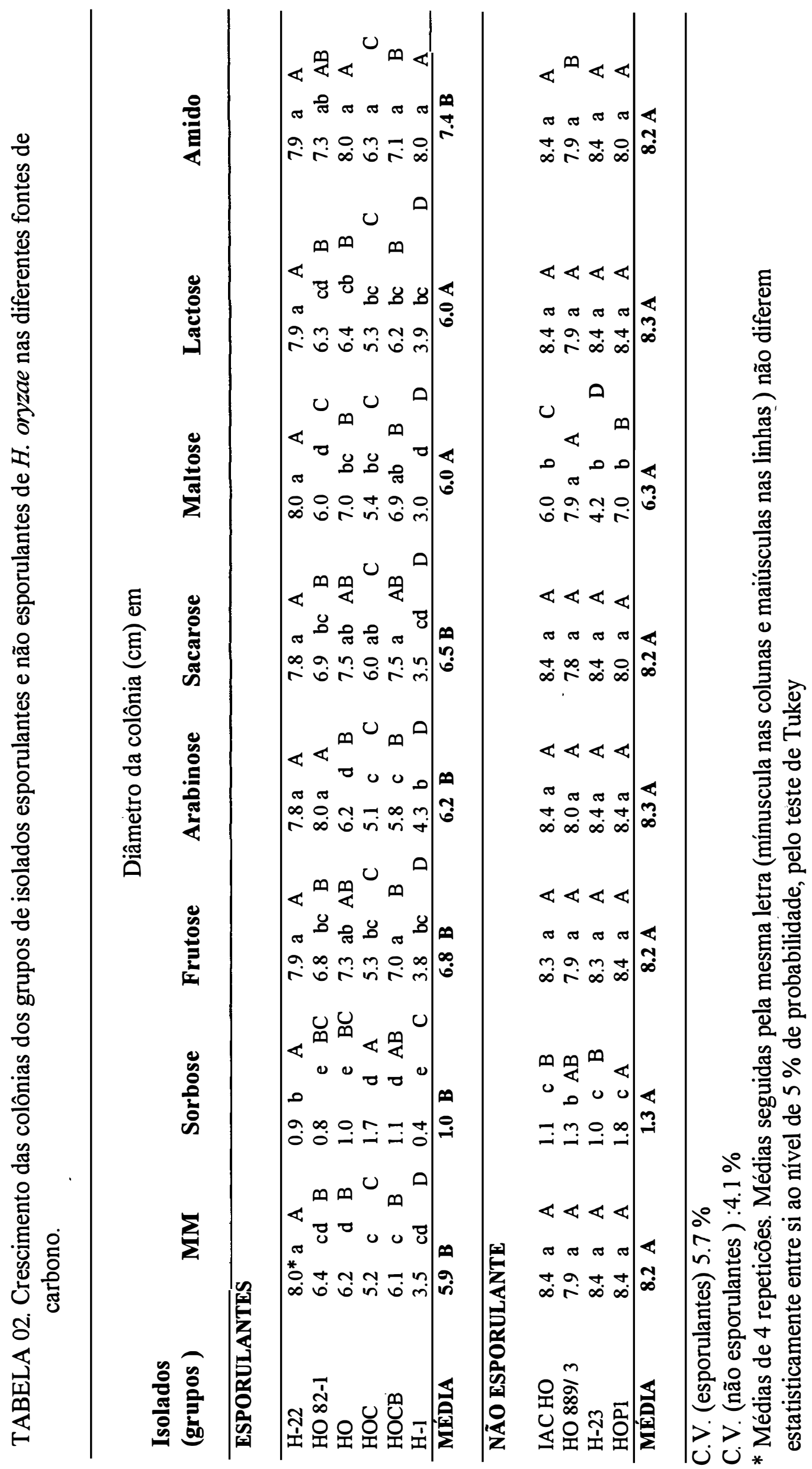


HO 82-1, ao contrário do anterior, o meio com arabinose proporcionou melhor crescimento, o qual não diferiu do meio com amido.

Tanto para os isolados não esporulantes como para os esporulantes, dentro de cada grupo, não houve um açúcar que proporcionasse um crescimento significativamente melhor, diferenciando-o de maneira marcante dos demais isolados, embora o amido tenha proporcionado bom crescimento de todos os isolados. Por outro lado, quando se comparou o crescimento dos grupos de isolados esporulantes e não esporulantes para cada açúcar, verificou-se diferenças significativas entre os grupos, sendo que apenas com a maltose como fonte de carbono não houve diferenças entre eles.

\subsubsection{Fontes de nitrogênio}

$\mathrm{Na}$ Tabela 03 estão apresentados os valores do diâmetro das colônias dos isolados não esporulantes e esporulantes de $H$. oryzae, respectivamente, crescendo em meio mínimo suplementado com nitrogênio orgânico e inorgânico. Todos os isolados tiveram boa capacidade de assimilar a maioria das fontes orgânicas e inorgânicas.

Entre os isolados não esporulantes, não houve diferenças em relação ao uso da neopeptona, caseína, asparagina e uréia, todos os quais permitiram um excelente desenvolvimento micelial. O cloreto e o sulfato de amônio foram as fontes de nitrogênio que proporconaram em geral, menor crescimento micelial, principalmente para o isolado $\mathrm{H}-23$.

Entre os isolados esporulantes, O isolado $\mathrm{H} \neg 22$, destacou-se pelo seu excelente desenvolvimento na maioria 


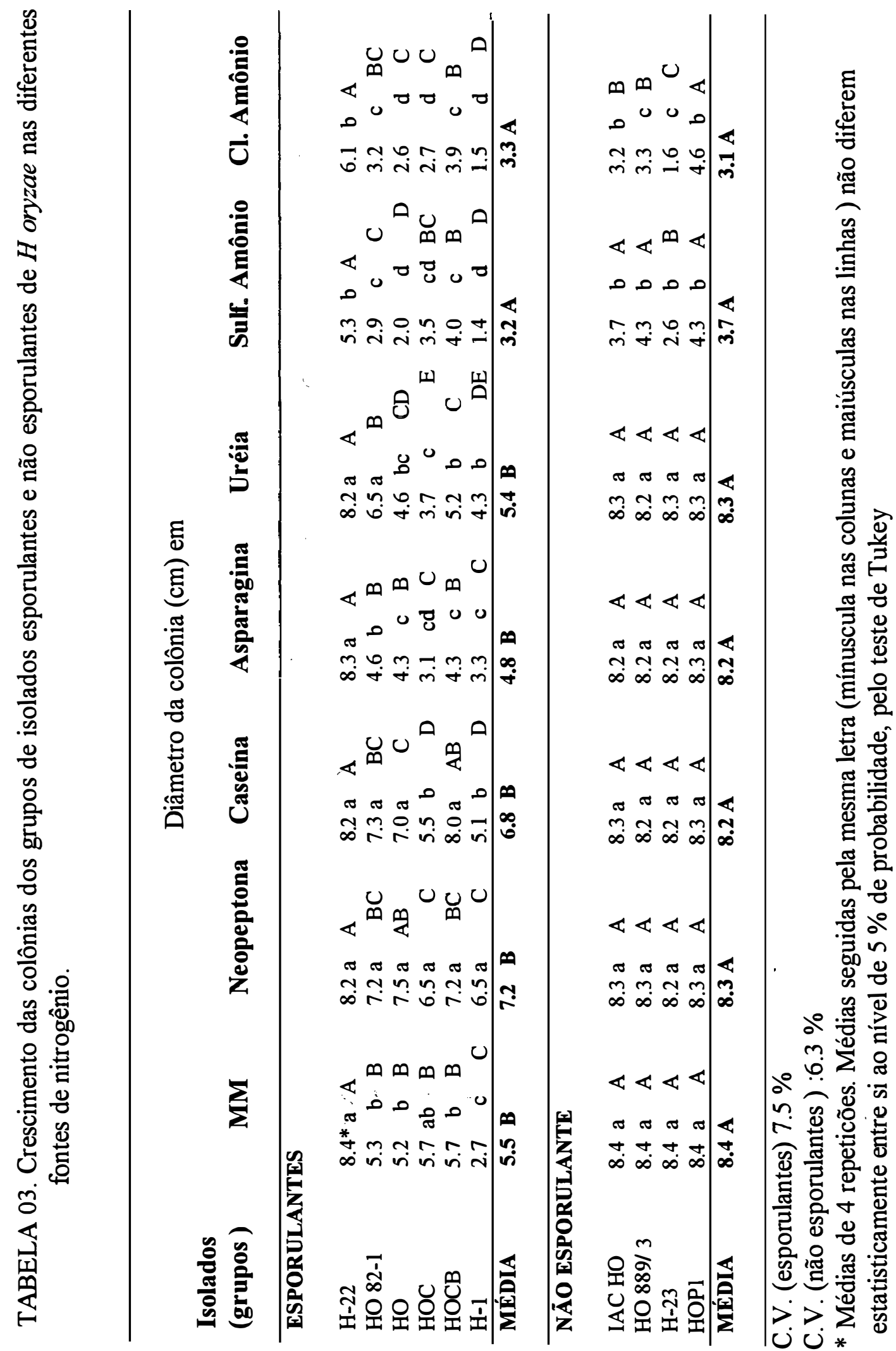


das fontes de nitrogênio testadas, e embora apenas na presença do sulfato e cloreto de amônio tenha apresentado crescimento menor, este foi melhor que o dos demais isolados nestes sais. Neopeptona foi uma fonte de nitrogênio favorável para todos os isolados, apesar do crescimento nesta fonte não ter diferido daquele em meio suplementado com caseína para a maioria dos isolados ( $\mathrm{H}-22$, HOCB e HO 82-1). Comportamento semelhante foi observado para 0 isolado HO 82-1 em meio mínimo suplementado com uréia, não diferindo estatisticamente dos açúcares acima citados. Por sua vez, os isolados $\mathrm{H}-1$ e HOC apresentaram em geral, menor diâmetro da colônia que os demais isolados, independentemente da fonte de nitrogênio.

Através deste estudo, pôde-se observar que nenhum dos isolados exibiu preferência contrastante por determinada fonte de nitrogênio, o que poderia diferenciá-lo dos demais, mas a neopeptona sempre proporcionou melhor crescimento para todos os isolados, embora, na maioria das vezes, o crescimento não tenha diferido daquele nas demais fontes de nitrogênio.

Quando se comparou o crescimento do grupo dos isolados esporulantes e do não esporulantes em cada fonte de nitrogênio, verificou-se diferenças significativas; exceção para o cloreto e sulfato de amônio, onde não houveu diferenças. 


\subsubsection{Mistura de aminoácidos}

Os resultados de crescimento das colônias dos isolados não esporulantes e esporulantes, crescendo em meio mínimo suplementado com misturas de aminoácidos são apresentados na Tabela 04. Entre os isolados não esporulantes, houve uniformidade em relação ao uso dos aminoácidos dos grupos I e II, sendo que em todos os tratamentos houve bom desenvolvimento micelial.

Entre os isolados esporulantes, 0 isolado $\mathrm{H}-22$ destacou-se pelo seù melhor desenvolvimento micelial independentemente do grupo de aminoácidos utilizados, e o isolado $\mathrm{H}-1$ apresentou o menor crescimento micelial em relação aos demais isolados.

$\mathrm{Na}$ análise entre os grupos de isolados esporulantes e não esporulantes foi posssível constatar diferenças significativas entre os mesmos.

\subsection{Efeito comparativo da nutrição na esporulação de} isolados de $H$. oryzae

\subsubsection{Açúcares}

Os resultados sobre a esporulação dos isolados esporulantes de H. oryzae, estão apresentados na Figura 02 . Entre os isolados de H. oryzae destacaram-se HOCB e HO como os de maior esporulação, observando-se que a maltose e a glicose do meio mínimo permitiram uma maior esporulação no primeiro caso, enquanto que para o isolado Ho o meio onde 
TABELA 04. Crescimento das colônias dos grupos de isolados esporulantes e não esporulantes de $H$ oryzae nas diferentes grupos de aminoácidos.

Isolados

Diâmetro da colônia $(\mathrm{cm})$ em

(grupos)

MM.

AA G I

AA G.II

ESPORULANTES

$--\cdot$

\begin{tabular}{lllllllllll} 
H-22 & $8.4 *$ & a & A & 8.2 & a & A & & 8.4 & a & A \\
HO 82-1 & 5.3 & b & B & 4.0 & c & B & 6.9 & a & B \\
HO & 5.2 & b & B & 4.2 & b & B & 5.6 & a & C \\
HOC & 5.7 & ab & B & 4.0 & c & C & 4.5 & b & D \\
HOCB & 5.7 & b & B & 4.2 & b & B & 5.7 & b & B \\
H-1 & 2.7 & b & C & 2.8 & b & C & 4.0 & a & D \\
\hline MÉDIA & 5.5 & B & & & 4.5 & B & & 5.9 & B & \\
\hline
\end{tabular}

\section{NÃO ESPORULANTE}

$\begin{array}{llllllllll}\text { IAC HO } & 8.4 & \text { a } & \text { A } & 8.3 & \text { b } & \text { A } & 8.3 & \text { b } & \text { A } \\ \text { HO 889/ 3 } & 8.4 & \text { a } & \text { A } & 8.3 & \text { b } & \text { A } & 5.3 & \text { b } & \text { A } \\ \text { H-23 } & 8.4 & \text { a } & \text { A } & 8.3 & \text { b } & \text { A } & 5.2 & \text { b } & \text { A } \\ \text { HOPl } & 8.4 & \text { a } & \text { A } & 8.3 & \text { b } & \text { A } & 5.7 & \text { b } & \text { A }\end{array}$

\section{MÉDIA}

$8.4 \mathrm{~A}$

$8.3 \mathrm{~A}$

8.3 A

C.V. (esporulantes) $5.5 \%$ :

C.V. (não esporulantes ) $: 0.17 \%$

* Médias de 4 repeticões. Médias seguidas pela mesma letra (mínuscula nas colunas e maiúsculas nas linhas ) não diferem estatisticamente entre si ao nivel de $5 \%$ de probabilidade, pelo teste de Tukey 

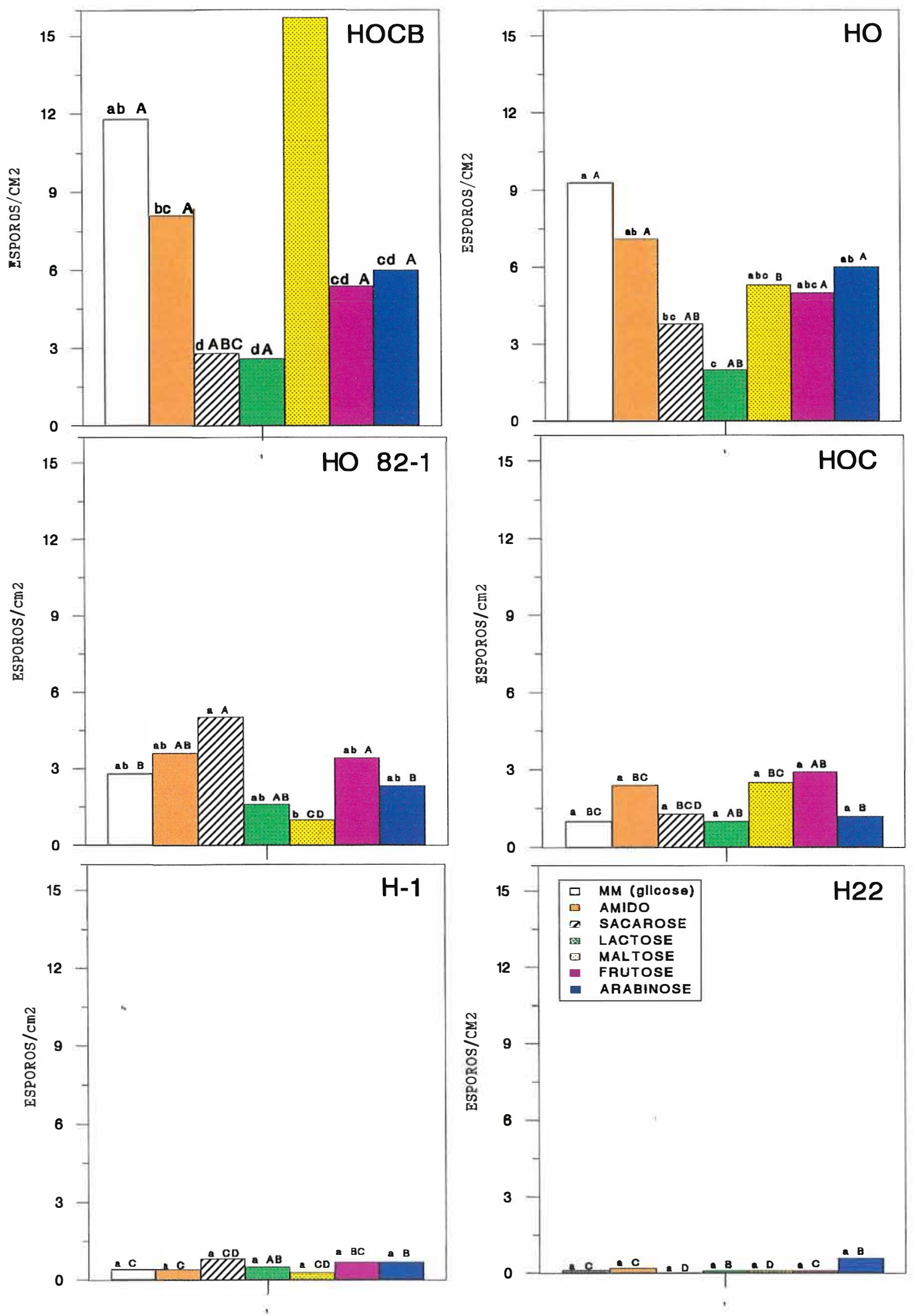

Figura 02. Esporulação $\left(10^{3}\right.$ esporos $\left./ \mathrm{cm}^{2}\right)$ dos isolados esporulantes de $H$. oryzae em meio mínimo suplementado com diferentes fontes de carbono, após 7 dias de incubação a $28^{\circ} \mathrm{C}$. Médias seguidas pela mesma letra maiúscula ou minúscula não diferem entre si para o mesmo tratamento em cada isolado, ou mesmo isolado para diferentes tratamentos, respectivamente, pelo teste de Tukey. 
foi adicionado glicose permitiu esporulação maior em relação com os demais açúcares. Para os isolados restantes não destacou-se nenhum açúcar favorecendo a esporulação. Os isolados $\mathrm{H}-1$ e $\mathrm{H}-22$ diferenciaram-se dos restantes pela baixíssima taxa de esporulação.

\subsubsection{Nitrogênio}

Na Figura 03 estão apresentados os resultados do efeito das diferentes fontes de nitrogênio na esporulação dos isolados esporulantes de $H$. oryzae. Verificou-se um comportamento semelhante ao dos estudos com açúcares. Houve isolados com alta taxa de esporulação (HOCB e HO 82-1), outro com taxa intermediária (HOC) e outros com baixa taxa $(\mathrm{H}-1$ e $\mathrm{H}-22)$.

No caso dos isolados HO e HOCB ao se suplementar uréia no meio mínimo, houve uma maior esporulação em relação às demais fontes de nitrogênio, sendo que o isolado HO 82-1 foi mais favorecido pela asparagina. Os demais isolados esporularam pouco, independente da fonte de nitrogênio estudada.

\subsubsection{Mistura de aminoácidos}

Na Figura 04 encontram-se os resultados do efeito das misturas de aminoácidos pertencentes aos grupos I e II na esporulação dos isolados esporulantes de $H$. oryzae. Verificou-se que, na maioria dos casos, houve escassa diferença entre os tratamentos, com um comportamento variável. Para o isolado HoC, O meio mínimo suplementado com nitrato de sódio permitiu a maior taxa de esporulação, o que também aconteceu com o isolado $\mathrm{H}-1$. Os isolados $\mathrm{H}-22$ 
e H-1 igualmente aos estudos anteriores, apresentaram sempre baixa produção de esporos.

Durante os estudos nutricionais verificou-se que a capacidade de esporulação abundante ou não dos isolados de H. oryzae é mais uma característica própria do isolado, tendo as fontes de carbono e nitrogênio pouca influência na esporulação.

Para os isolados não esporulantes, a presença no meio mínimo de determinadas fontes de carbono, nitrogênio e aminoácidos não induziu a esporulação. 

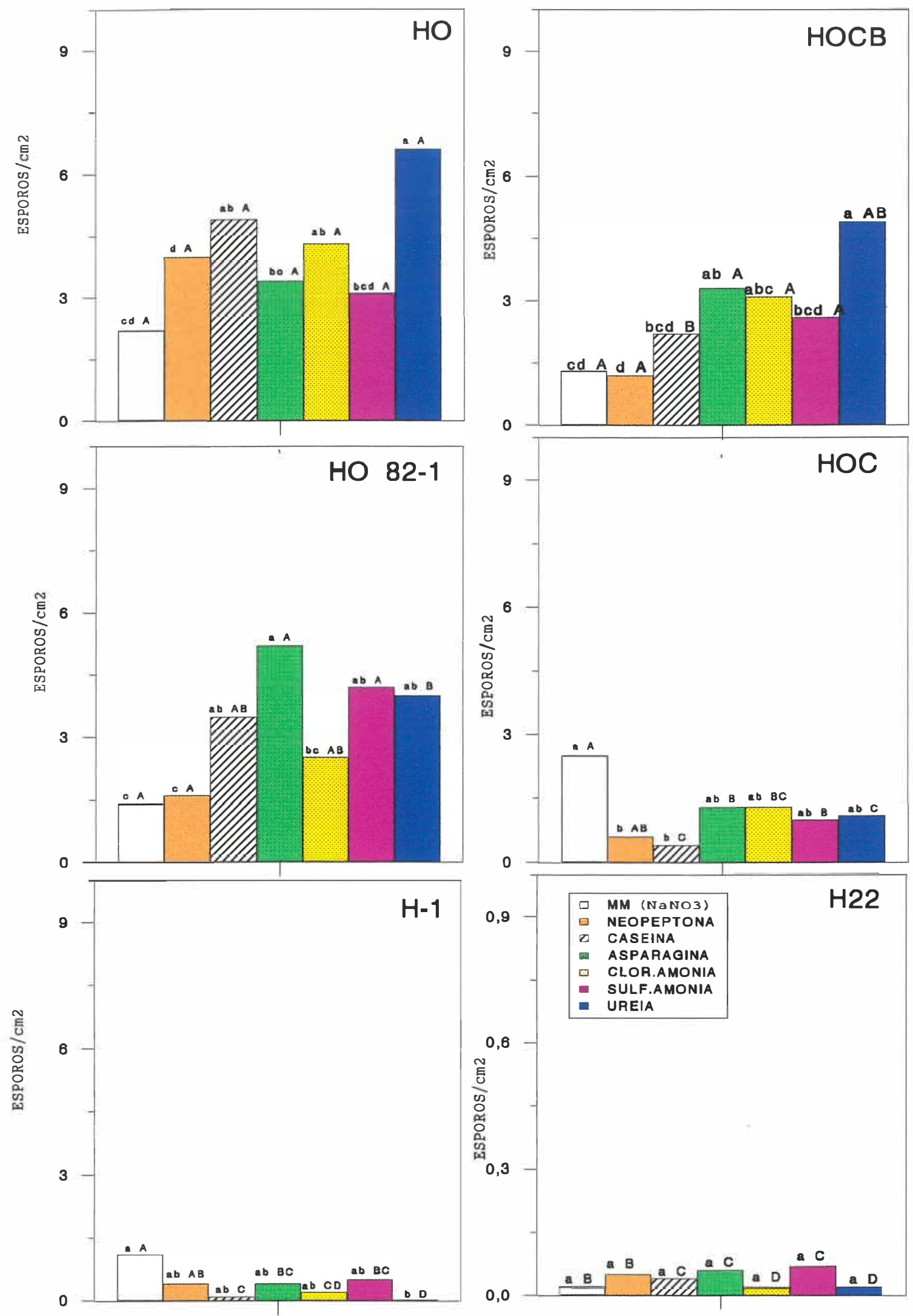

Figura 03. Esporulação $\left(10^{3}\right.$ esporos $\left./ \mathrm{cm}^{2}\right)$ dos isolados esporulantes de $H$. oryzae em meio mínimo suplementado com diferentes fontes de nitrogênio, após 7 dias de incubação a $28{ }^{\circ} \mathrm{C}$. Médias seguidas pela mesma letra maiúscula ou minúscula não diferem entre si para o mesmo tratamento em cada isolado, ou mesmo isolado para diferentes tratamentos, respectivamente, pelo teste de Tukey. 

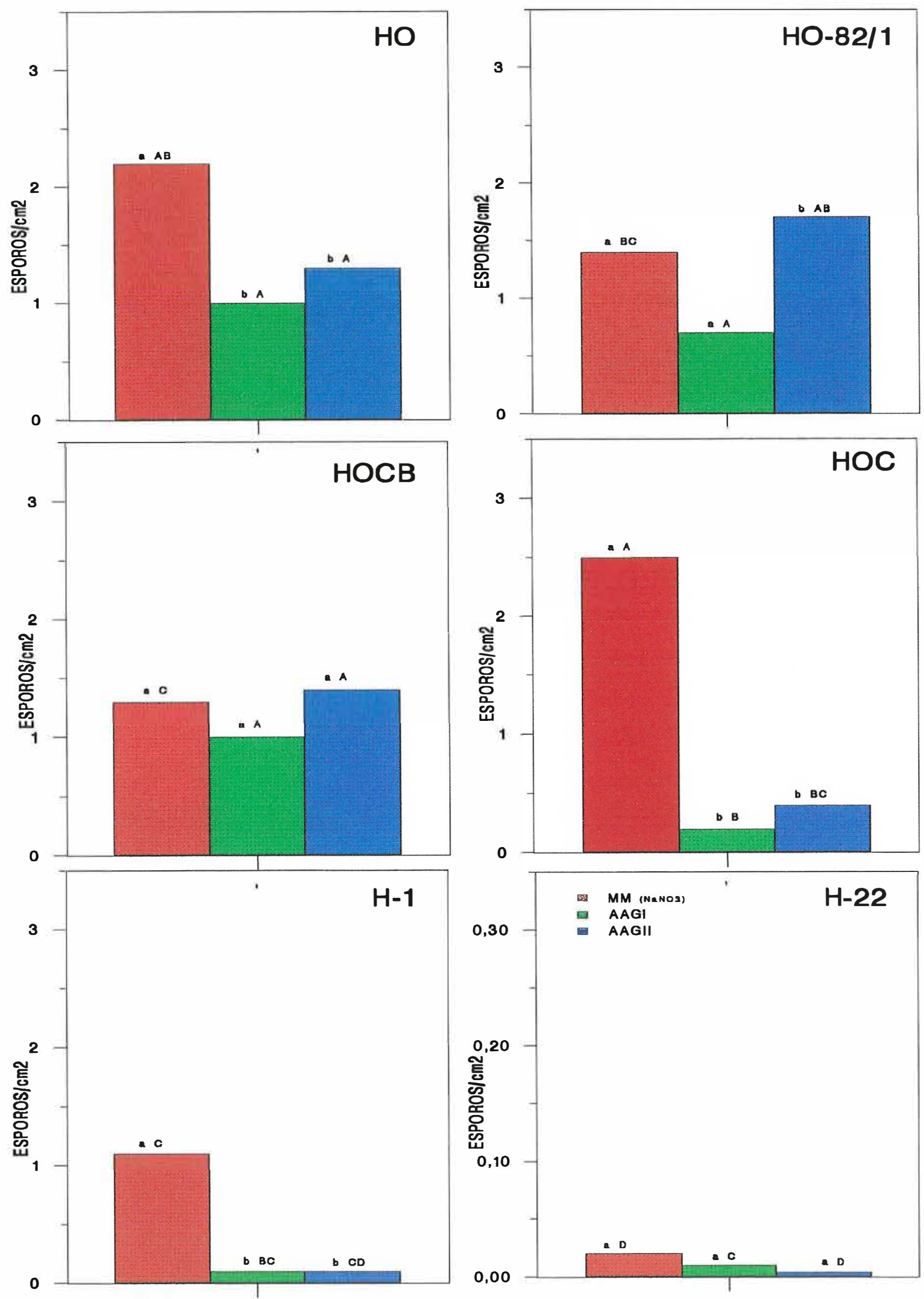

Figura 04. Esporulação $\left(10^{3}\right.$ esporos $\left./ \mathrm{cm}^{2}\right)$ dos isolados esporulantes de $H$. oryzae em meio mínimo suplementado com diferentes grupos de aminoácidos, após 7 dias de incubação a $28^{\circ} \mathrm{C}$. Médias seguidas pela mesma letra maiúscula ou minúscula não diferem entre si para o mesmo tratamento em cada isolado, ou mesmo isolado para diferentes tratamentos, respectivamente, pelo teste de Tukey. 


\subsection{Eletroforese}

A análise e a interpretação dos resultados obtidos, foram efetuados com base na observação direta dos géis, diagrama esquemático e análise densitométrica.

Nas Figuras 05, 06 e 07 constata-se que entre os isolados esporulantes, a maioria apresentou 2 bandas comuns com Rm (mobilidade relativa) 3,6-3,9; 4,1-4,3. Porém, os isolados $\mathrm{H}-22$ e H-1 exibiram 4 e 3 bandas, respectivamente, tendo uma banda em comum com $\mathrm{Rm} 3,6-3,8$, sendo as demais características com $\operatorname{Rm} 3,2-3,4 ; 4,0-4,1 ; 4,4-4,6 ; 5,3-5,6$ e $3,0-3,2 ; 4,1-4,3$, respectivamente.

Entre os isolados não esporulantes, houve alguns apresentando 1, 2 ou 3 bandas com intensidades diferentes na faixa de $\mathrm{Rm}$ 3,0-5,0. Por sua vez, o isolado IAC-HO apresentou duas bandas comuns aos isolados esporulantes, entretanto, o mesmo não esporulou in vitro. 0 mesmo comportamento apresentou o isolado HO-P1, pela presença de uma só banda comum aos esporulantes.

Em relação aos isolados não esporulantes HO 899/3 e H-23, mesmo apresentando 3 bandas, estas foram de baixa intensidade, sendo uma comum aos isolados esporulantes com Rm 3, 8-4, 0 . 

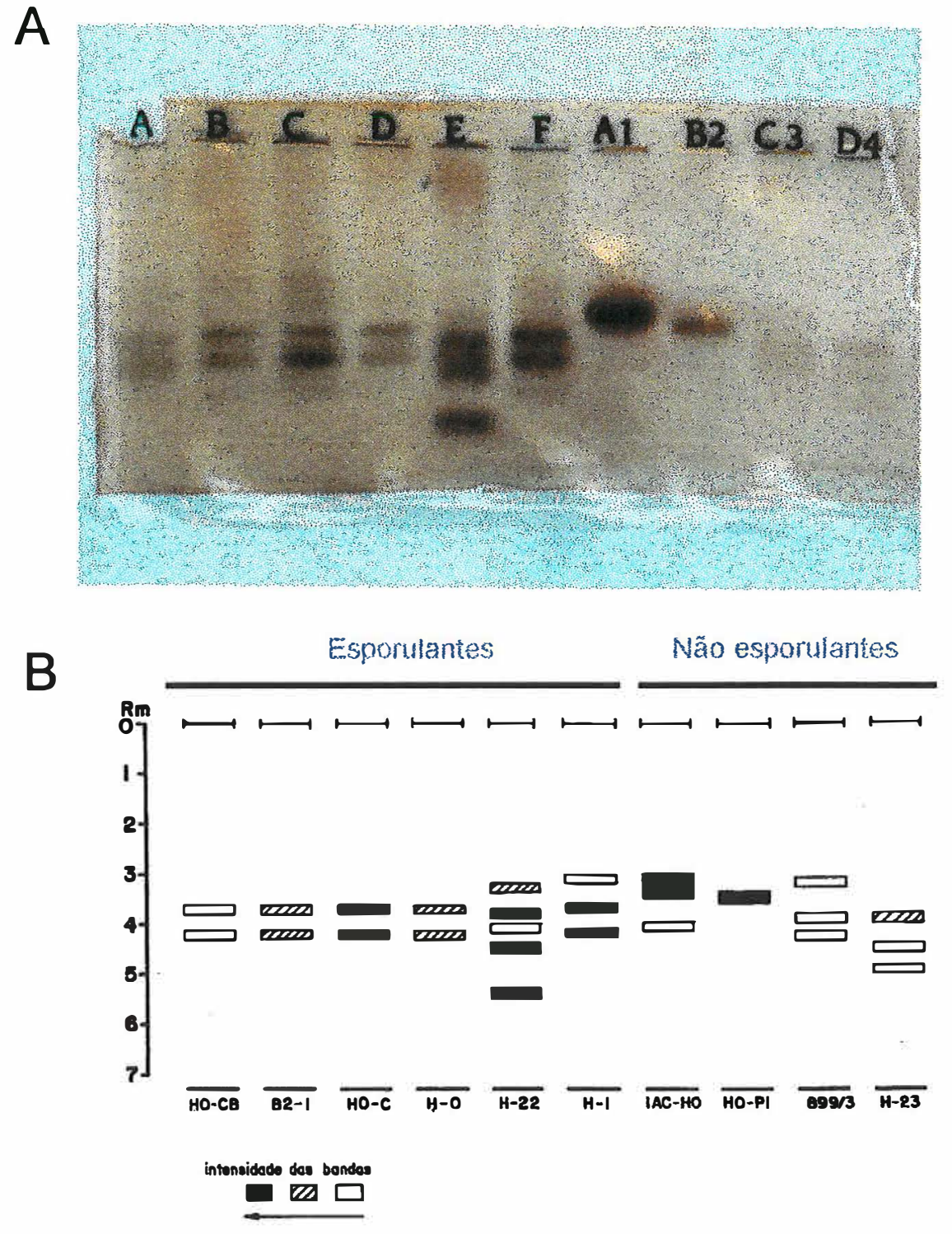

Figura 05. A] Eletroforese em gel de poliacrilamida dos isolados esporulantes $(A=H O C B$, $B=H O$ 82-1, C = HOC, $D=H O, E=H-22, F=H-1)$ e não esporulantes $(A 1=\mid A C-H O, B 2=$ HOP1, C3= HO 899/3, D4= H-23) de $H$. oryzae. B] Diagrama eletroforético em gel de poliacrilamida dos isolados esporulantes e não esporulantes de $H$. oryzae. 


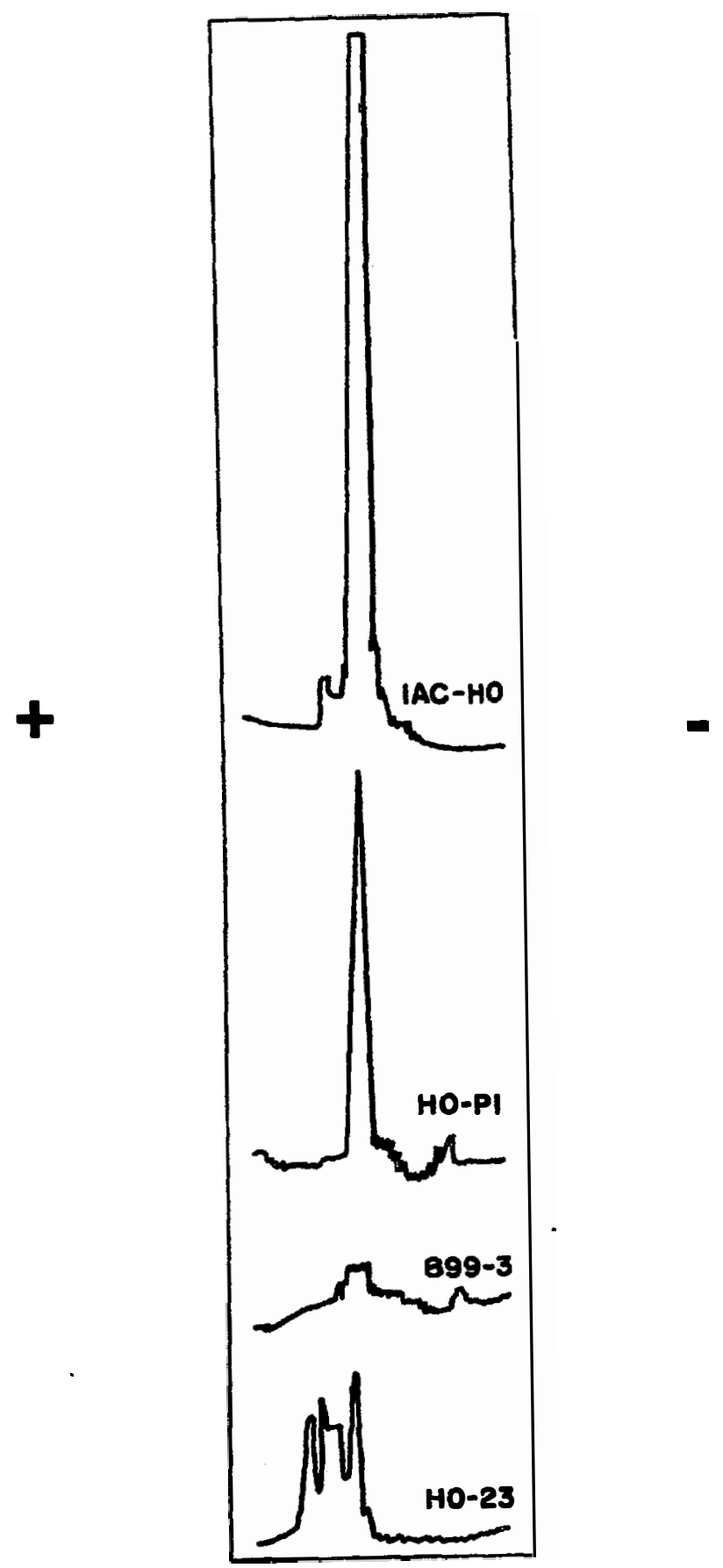

Figura 06. Densitometria dos isolados não esporulantes de $H$. oryzae. Leitura em filtro de $545 \mathrm{~nm}$. 


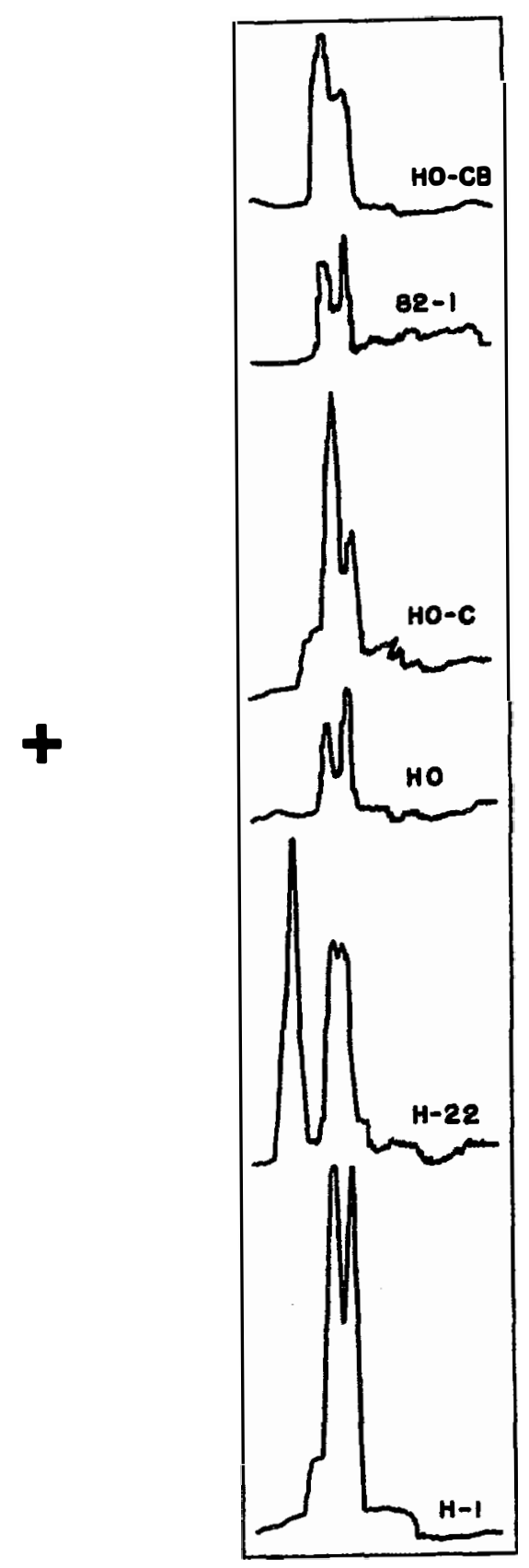

Figura 07. Densitometria dos isolados esporulantes de $H$. oryzae. Leitura em filtro de $545 \mathrm{~nm}$. 


\section{DISCUSSÃO}

\subsection{Efeito comparativo da nutrição no crescimento.}

Nos estudos nutricionais, os resultados mostraram que $H$. oryzae pode utilizar monossacarídeos (frutose, arabinose), dissacarídeos (sacarose e maltose) e polissacarídeos (amido) como fontes de carbono, concordando com os resultados encontrados por Das \& Baruah ${ }^{3}$ citado por OU (1985), onde a glicose, sacarose e o amido forneceram o máximo crescimento micelial de $H$. oryzae. Tanaka ${ }^{4}$ citado por OU (1985) verificou, em estudos nutricionais feitos em meio Czapek que a xilose, glicose, frutose, manose, galactose, sacarose e maltose permitiram um bom crescimento micelial desse fungo. CHATTOPADHYAY \& DAS GUPTA (1965) também encontraram 0 amido como boa fonte de crescimento dos oito isolados testados. A L(-)sorbose permitiu um mínimo crescimento dos isolados de $H$. oryzae, sendo relatos semelhantes encontrados em estudos nutricionais com outros gêneros de fungos. Segundo MAAS \& POWELSON (1972), os fungos diferem na sua habilidade para utilizar a sorbose, um açúcar que raramente ocorre na natureza. Por sua vez,

\footnotetext{
${ }^{3}$ DAS,C.R.; BARUAH,H.K. experimental studies on the parasitism of rice by Helminthosporium oryzae Breda de Haan and its control in field and storage. Transactions of the Bose Research Institute, 16:31$46,1947$.

${ }^{4}$ TANAKA, H. On the influence of the carbon source upon the growth of Cochliobolus mijabeanus, Forchungen aus dem gebiet der Pflanzkrankheiten, 5:165-70,1956.
} 
LILLY \& BARNETT (1953) indicam que a incapacidade de usar a sorbose é uma questão de adaptabilidade dos fungos, podendo portanto agrupá-los de acordo com essa habilidade.

Durante 0 presente estudo, pôde-se observar que 0 comprimento da fase lag do crescimento, com o uso da sorbose, diferiu entre os isolados de $H$. oryzae. Resultados semelhantes foram obtidos por ELLIS et al. (1973) que observaram diferenças entre as raças de Helminthosporium carbonum na capacidade de usar sorbose.

No tocante aos estudos comparativos com diferentes fontes orgânicas de nitrogênio, pôde-se observar que a maioria serviu como fonte nutricional, fornecendo um bom crescimento. Os trabalhos de MISRA \& MUKERJEE (1962) indicaram que a peptona e a uréia suportam um bom crescimento micelial de H.oryzae.

Quando o meio mínimo foi suplementado com sais de sulfato e cloreto de amônia, todos os isolados de $H$. oryzae se mostraram deficientes na utilização destes sais de amônio. Essa deficiência no uso possivelmente esteja relacionada a uma queda de $\mathrm{pH}$, como explicado por COCHRANE (1958) •

Em termos gerais, foi constatado que os isolados não esporulantes apresentaram crescimento mais rápido que os esporulantes, contrastando com os resultados obtidos por SINGH (1967), que observou que os isolados esporulantes de H. oryzae tinham um crescimento mais rápido em meio Richards sólido. Essas diferenças possivelmente se devem às condições de cultivo, já que os meios usados foram diferentes que os do presente trabalho.

No tocante ao uso destes estudos nutricionais como uma ferramenta auxiliar para se comparar e diferenciar 
isolados de $H$. oryzae, a mesma não mostrou-se eficiente. Porém, é um método aplicável a outros gêneros de fungos, como relata o trabalho de MALCA \& ULLSTRUP (1962), que observaram diferenças entre isolados de $H$. carbonum e $H$. turcicum no crescimento e esporulação, dependendo da nutrição de carbono e nitrogênio. ELLIS et al. (1973), também observaram diferenças entre raças de $H$. carbonum na preferência por determinados açúcares e habilidade de usar a L-sorbose. BONNELL et al. (1981) observaram diferenças entre raças de Epicoccum nigrum na utilização preferencial de certos açúcares.

\subsection{Efeito comparativo da nutrição na esporulação}

No presente trabalho verificou-se uma grande variabilidade no tọcante a esporulação entre os isolados de H. oryzae, desde aqueles com uma baixíssima taxa de esporulação, como os isolados $\mathrm{H}-22$ e $\mathrm{H}-1$, até aqueles exibindo abundante esporulação, como HO e HOCB. Essa variabilidade entre isolados de $H$. oryzae também foi observado por SREEDHARAM \& MENON (1974), onde existiam isolados com abundante formação de esporos e isolados de esporulação muito esparsa. Porém, entre os isolados de $H$. oryzae, não foi observada nenhuma variabilidade na esporulação em resposta a uma determinada fonte de carbono ou nitrogênio, embora tenham existido efeito variado na taxa de esporulação.

A L(-)sorbose não propiciou boa esporulação, sendo que resultados semelhantes foram obtidos por MAAS \& POWELSON (1972), o qual verificou a não ocorrência de esporulação. de Botrytis convoluta em meio contendo sorbose. 
No caso do isolado HO 82-1, todas as fontes de nitrogênio permitiram uma boa esporulação, 0 que complementa o resultado obtido por MASSOLA \& BEDENDO (1993) que encontraram uma melhor esporulação desse isolado em meio de BDA suplementado com peptona.

CHATTOPADHYAY \& DAS GUPTA (1965) estudando o efeito da glicose, amido e sacarose na esporulação de Helminthosporium oryzae, observaram que o amido foi o melhor e glicose foi uma fonte pobre de carboidratos para tal fim. No presente trabalho, por outro lado, verificou-se esporulação semelhante com a maioria dos açúcares testados, sendo que a glicose proporcionou esporulação semelhante ou melhor que os demais açúcares.

No tocante ao efeito das fontes de nitrogênio na produção de esporos, esta variou bastante entre os isolados, contrastando com aqueles obtidos por CHATTOPADHAYAY \& DAS GUPTA (1965), onde o nitrato de potássio, a asparagina e o ácido glutâmico favoreceram a produção de conídios. Os sais de amônia, alanina, tirosina e triptofano mostraram-se como fontes de nitrogênio pobres para a produção de conídios. Essas diferenças se devem possivelmente aos diferentes meios basais usados nos experimentos. O efeito das diferentes fontes de nitrogênio foi variável, sem destacar-se nenhuma como ótima, exceto a uréia para os isolados HO e HOCB.

Com respeito aos isolados não esporulantes de $H$. oryzae, pode-se observar que nenhum dos tratamentos com açúcares, nitrogênio e misturas de aminoácidos tiveram efeito de indução da esporulação. Esses resultados concordam com aqueles obtidos por SINGH (1967), que observou que várias fontes de carbono, nitrogênio, hormônios, vitaminas, agentes mutagênicos, e substâncias 
"staling" falharam na indução da esporulação dos isolados não esporulantes. Porém, com a adição de vitaminas e penicilinas e incubação sob condições de fotoperíodo, escuro e luz contínua exibiram a máxima formação de clamidósporos.

Segundo CHATTOPADHYAY \& DAS GUPTA (1965), os estudos sobre a esporulação de isolados de $H$. oryzae sob diferentes condições fisiológicas, mostra que os mesmos podem ser agrupados em dois tipos: aqueles que esporulam de maneira dispersa e aqueles que esporulam de maneira abundante. Por outro lado, a formação de conídios pode ser um caráter intrínseco do isolado, porém os isolados não parecem diferir um' do outro em relação aos requerimentos nutricionais, mas diferentes compostos de carbono e nitrogênio possuem efeitos diferentes na esporulação.

\subsection{Eletroforese}

O sistema isoenzimático de esterases permitiu estabelecer diferenças entre os padrões dos isolados esporulantes e não esporulantes de Helminthosporium oryzae. Foi observado por SHIPTON \& MCDONALD (1970) através de eletroforese em gel de poliacrilamida, diferenças entre os padrões de proteínas extraídas de esporos e de micélio de Drechslera erythrospilum e D. teres, a nível intra e interespecífico, principalmente no referente a número de bandas, porém, também houve diferenças na largura e intensidade das mesmas.

Os resultados, destacam também que a maioria dos isolados esporulantes (HOCB; HO82-1; HO-C; HO; H-22 e H-1) apresentaram maior atividade da esterases (maior intensidade de cor das bandas) em relação aos não 
esporulantes (IAC-HO; HOPI; HO 899/3 e H-23). Alguns autores explicam que esta diferença na atividade da esterase está relacionada a fase de esporulação e consideram que a atividade desta pode ser usada para evaliar o estado de desenvölvimento de uma cultura (CUNNINGHAM \& KUIACK, 1989). LLOYD et al. (1971) mostraram também que a atividade da esterase está sempre asssociada com a conidiação, independentemente do tipo de meio.de esporulação .

Isto indica a utilidade dos estudos envolvendo o uso da atividade da esterase para ressaltar a esporulação de um fungo e diferenciar isolados esporulantes e não esporulantes com características culturais muitas vezes semelhantes.

Algo que destacou-se nos padrões esporulantes foi a ocorrência de duas bandas comuns à maioria dos isolados, exceto para os isolados $\mathrm{H}-1$ e $\mathrm{H}-22$, que nos estudos nutricionais apresentaram um comportamento totalmente diferente aos demais, como baixa esporulação. Uma possível explicação para isto seria que nesse momento estaria ocorrendo uma degradação dessas duas bandas necessárias para a esporulação e agora derivadas a formação de micélio. Além dessas suposições, o que fica claro é a utilidade dos padrões de esterases como um método para diferenciar isolados, que é ilustrado pelos trabalhos de vários autores, como BACH (1991), para estabelecer diferenças entre isolados de Exserohilum turcicum, FANCELLI (1991) establecendo diferenças entre os isolados de Alternaria solani e GOES (1995) possibilitando encontrar diferenças entre os isolados de Colletotrichum gloeosporioides. 


\section{CONCLUSÕES}

Os resultados obtidos no presente trabalho permitiram as seguintes conclusões:

1) Os estudos comparativos a nível nutricional não permitiram se estabelecer diferenças marcantes entre os isolados de Helminthosporium oryzae, mostrando-se um método pouco consistente para a caracterização dos isolados. Por outro lado, permitiram conhecer o amplo espectro de fontes de carbono e nitrogênio que podem ser usadas por $H$. oryzae;

2) O efeito das fontes de carbono e nitrogênio mostrou-se variável, não se destacando nenhuma como ótima para a produção de esporos pelos diferentes isolados de $H$. oryzae;

3) Observou-se uma grande variabilidade entre os isolados quanto à taxa de esporulação, independente das fontes de carbono e nitrogênio estudadas, sendo esta possivelmente uma característica inerente do isolado e pouco influenciada pelos fatores nutricionais;

4) A análise eletroforética das isoenzimas da esterase permitiram estabelecer diferenças entre os isolados, as quais podem ser correlacionadas com a taxa de esporulação dos mesmos. 


\section{REFERÊNCIAS BIBLIOGRÁFICAS}

ALFENAS, A.C. Aplicações da eletroforese de proteínas e isoenzimas em fitopatologia. In: ENCONTRO SOBRE APLICAÇÃO DA ELETROFORESE NA AGROPECUÁRIA, 3., Nova Odessa, 1991. Nova Odessa, Instituto de Zootecnia. p.14-29.

AZEVEDO, J.L. de Genética dos Fungos I-Mutantes. Ciclo sexual e Ciclo parasexual In: Gênetica fisiológica e de microorganismos. Parte II Publicações Didáticas. Instituto de Genética - ESALQ/USP - Piracicaba - São Paulo, 1972. p. 371-397.

BACH, E.E. Comparação morfológica, patogênica, serológica e eletroforética de Exserohilum turcicum (Pass.)Leonard \& Suggs, isolado de milho, sorgo e capim Massambará: Piracicaba, 1991. 137p. (Mestrado - Escola Superior de Agricultura "Luiz de Queiroz"/USP) .

BEADLE , G.W. \& TATUM, E.L. Neurospora II Methods of producing and detecting mutations concerned whit nutritional requeriments. American Journal of Botany, $32: 678-686,1945$.

BONDE, R.M.; MICALES, A.J.; PETERSON, L.G. The use of isoenzime analysis for identification of plantpathogenic fungi. Plant Disease, St. Paul, 77(10): 961$7,1993$. 
BONNELL, S.B. \& LEVETIN, E. The influence of nutrition on the growth and sporulation of two strain of Epicoccum nigrum. Mycologia, Lancaster, 73: 235-43, 1981.

CAO, W. \& CRAWFORD, D.L. Carbon nutrition and hydrolytic and cellulolytic activities in the ectomycorrhizal fungus Pisolithus tinctorius. Canadian Journal of Microbiology, Ottawa, 39: 529-35, 1993.

CHATTOPADHYAY, S.B. \& DAS GUPTA, C. Factors affecting conidial production of Helminthosporium oryzae. Indian Phytopathology, Lancaster, 18: 160-7, 1965.

$\bar{x}$

CRUICKSHANK, R.H. \& PITT, J.I. Identification of especies in Penicillium sugenus Penicillium by enzime electrophoresis. Mycologia, Lancaster, 79(4): 614-20, 1987 .

COCHRANE, V.W. Physiology of fungi. New York, JOHN WILEY \& SONS, INC, 1958. $524 \mathrm{p}$.

CUNNINGHAM, J.E. \& KUIACK, C. Esterase activity as a marker for sporulation in Colletotrichum gloeosporioides f. $\mathrm{sp}$ malvae in submerged culture. Mycological Research 93 (2) : 236-239. 1989 .

DUDIENAS, C. Caracterização morfológica, auxanográfica e patogênica de Colletotrichum gossypii South. e Colletotrichum gossypii south. var. cephalosporioides Costa \& Fraga Jr. Piracicaba, 1990. 67p. (Mestrado Escola Superior de Agricultura "Luiz de Queiroz"/USP). 
ELLIS, J.J; BENNETT, A.G, ; HESSELTINE, W.C. Uti-lization of carbon compounds by Helminthosporium maydis and $H$. carbonum. Mycologia, Lancaster, 65: 539-47, 1973.

FANCELLI, M.I. Comparação patogênica, cultural, serológica, e eletroforética entre isolados de Alternaria solani do tomate e da batata e variabilidade patogênica de A.solani f.sp lycopercisi N.F. Piracicaba, 1991. 80p. (Doutorado- Escola Superior de Agricultura "Luiz de Queiroz"/USP).

GARRAWAY, M.O.\& EVANS, R.C. Growth of fungi.' In: GARRAWAY, M.O.\& EVANS, R.C. ed. Fungal nutrition and physiology, USA, John Wiley \& Sons Inc., 1984. p.23163.

GEORG, K.L. \& CAMP, B.L. Routine nutritional test for the identification of Dermatophytes. Journal of Bacteriology, Baltimore, 74: 114-25, 1957.

GÓES, A. Queda prematura dos frutos cítricos: caracterização do agente causal, Colletotrichum gloeosporioides Penz. [Sensu Arx, 1957], e controle da doença. Piracicaba, 1995. 143p. (Doutorado- Escola Superior de Agricultura "Luiz de Queiroz"/USP).

HASIJA, K.S. Physiological studies of Alternaria citri and A.tenuis. Mycologia, Lancaster, 62: 289-95, 1970. 
HAU, F.C. A system for inducing sporulation of Bipolaris oryzae. Plant disease, St. Paul, 64(8): 788-89, 1980.

KIMATI, H. Taxonomia, esporulação e patogenicidade de Colletotrichum graminicola (Ces.) Wils [sensu ARX, 1957] Piracicaba, 1975. 103p. (Livre - docência- Escola Superior de Agricultura "Luiz de Queiroz"/USP).

KLECAN, A.L.; HIPPE, S.; SOMERVILLE, S.C. Reduced growth of Erysiphe graminis f.sp hordei induced by Tilletiopsis pallescens. Phytopathology, Lancaster, 80(4): 325-31, 1990 .

KOHN, L.M. Developimg new characters for fungal systematics: An experimental approach for determinig the rank of resolution. Mycologia, Lancaster, 84(2): 13953,1992 .

LILLY, V.G. \& BARNETT, H.L. Physiology of the fungi. New York, Mc Graw Hill Book Co., 1951. 464p.

LILLY, V.G. \& BARNETT, H.L. The utilization of sugars by fungi . West Va, University Agr. Experimental Station Bulletin, 362T, 1953. 58p.

LOWRY, O.H.; ROSENBROUGH, N.J.; FARR, A.L.; RANDALL, R.J. Protein measurement with the Folinphenol reagent. Journal Chemical, Baltimore, 193: 265-75, 1951. 
LLOYD, G.I.; MORRIS E. O. and SMITH, J.E. Astudy of esterases and their function in Candida lipolytica, Aspergillus niger and a yeast-like fungus. Journal of General Microbiology 63: 141-150.1971

MAAS, J.L. \& POWELSON, R.L. Growth and sporulation of Botrytis convoluta with various carbon and nitrogen sources. Mycologia, Lancaster, 64: 897-903, 1972.

MAGAE, Y.; HAGA, K.; TANIGUCHI, H.; SASAKI, T. Enzymes of strain of Pleurotus species Basidiomycetes compared by electrophoresis. Journal of Genetics Applied of Microbiology, Hyderabad, 36: 69-80, 1990.

MALCA, I. \& ULLSTRUP,J.A. Effects of carbon and nitrogen nutrition on growth and sporulation of two species of Helminthosporium. Bulletin of the Torrey Botanical Club, New York, 89(4): 240-9, 1962.

MASSOLA JR., N.S. \& BEDENDO, I.P. Produção de conidios por Helminthosporium oryzae. Influência da composição do meio de cultura, período de incubação, regime de luz e temperatura. Sumna Phytopatologica, Jaguariúna, $19(3 / 4): 157-61,1993$.

MISRA, A.P. \& MUKERJEE, A.K. Effect of carbon and nitrogen nutrition on growth and sporulation of Helminthosporium oryzae Breda de Haan. Indian Phytopathology, New Dehli, 15: $211-5,1962$. 
OU, S.H. Brown spot. In: Rice diseases. 2.ed., Farhan Royal, Commonwealth Mycologycal Institute, 1985. p.20122 .

PELLETIER, R.L. \& KEITT, G.W. Venturia inaequalis (Cke.) Wit. VI. Aminoacids as sources of nitrogen. American Journal of Botany, Baltimore, 41: 362-71, 1954.

PONTECORVO, G.; ROPER, J.A.; HEMMONS, L.M.; MC DONALD, K.D.; BUFTON, A.W.J. The genetics of Aspergillus nidulans. Advances in genetics, New York, 5: 141-238, 1953 .

PRABHU, A.S. Situação atual das doenças de arroz de sequeiro e estratégias de controle. In: CONGRESSO BRASILEIRO DE FITOPATOLOGIA, 28, Ilhéus, 1995. Resumos. Fitopatologia Brasileira, Brasilia, 20: 277, 1995. (suplemento).

SANTOS, R.G \& SANTOS, J. Incidência de doença em arroz irrigado no Estado do Tocantins. In: CONGRESSO BRASILEIRO DE FITOPATOLOGIA, 28, Ilhéus, 1995. Resumos. Fitopatologia Brasileira, Brasilia, 20: 345, 1995. (suplemento).

SHERF, A.F.; PAGE, R.M.; TULLIS, E.C.; MORGAN, T.L. Studies on factors affecting the infectivity of Helminthosporium oryzae. Phytopathology, St.Paul, 37: 281-90, 1947. 
SHIPTON, W.A. \& MCDONALD, W.C. The electrophoretic patterns of proteins extratectd from spores and mycelium of two Drechslera species.Canadian Journal of Botany 48: 10001002,1970

SHREEDHARAM, A. \& MENON, M.R. Effect of differet sources of carbon and nitrogen and tissue media on the cultural characters and pathogenicity of Helminthosporium oryzae Breda de Haan. Agricultural Research Journal of Kerala, Kerala, 8(1): 44-50, 1970.

SHREEDHARAM, A. \& MENON, M.R. Studies on the isolates of Helminthosporium oryzae. Indian Phytopathology, New Dehli, 27: 131-3, 1974 .

SINGH, P.J. A comparative study of four isolates of Helminthosporium oryzae Breda de Haan, and inducing sporulation in non-sporulating isolates. Science and culture, Calcutta, 33(3): 128-9, 1967.

TABER, R.A.; VANTERPOOL, T.C.; TALES W.A. A comparative nutritional study of Alternaria raphani; $A$. brassicae and $A$. brassicicola with special reference to $A$. Raphani. Phytopathology, St.Paul, 58: 609-16, 1968.

VALIM-LABRES, M.E.; PRESTES, A.M.; VAN DER SAND, S.T.; MATSUMURA, A.T.S. Variabilidade isoenzimática em populações de Bipolaris sorokiniana. Fitopatología Brasileira, Brasillia, 20: 344, 1995. (suplemento). 